\title{
Available Fault Protection Methods of Ungrounded AC Microgrids Evaluated by Transient Simulation Results
}

\author{
Keng-Yu Lien ${ }^{1}$, Duong Minh Bui ${ }^{*}$, Yung-Ruei Chang 3 , Yih-Der Lee ${ }^{3}$, Jheng-Lun Jiang3, \\ Ching-Chih Lin² \\ 1 Department of Avionics, China University of Science and Technology, Hsinchu, Taiwan. \\ ${ }^{2}$ Department of Electrical Engineering, Chung Yuan Christian University, Chungli, Taiwan. \\ ${ }^{3}$ Institute of Nuclear Energy Research, Atomic Energy Council, Taoyuan, Taiwan. \\ *Corresponding author. Tel. +886-978-844-211; email: duong.1041030@yahoo.com \\ Manuscript submitted September 26, 2015; accepted April 1, 2016. \\ doi: 10.17706/ijcee.2016.8.2.84-103
}

\begin{abstract}
This paper evaluates fault protection methods of ungrounded low-voltage (LV) AC microgrids (MGs) based on transient simulation results of a typical ungrounded LVAC microgrid. By considering operation characteristics of ungrounded MGs and a literature review on existing MG fault protection solutions in recent years, possible fault protection methods are proposed for an ungrounded AC MG. Transient simulation results of an ungrounded AC MG are obtained by line-to-line (LL) and line-to-ground (LG) faults, and operation transition tests of the microgrid between autonomous and grid-connected operation modes. Based on the simulation results, advantages and disadvantages of each ungrounded microgrid protection solution are highlighted. In order to get the optimal fault protection, combinations among some or all of possible fault protection solutions of an ungrounded LVAC microgrid are found out. As a result, main contributions of the paper contain: (i) proposing and analysing available fault protection solutions of ungrounded LVAC MGs, (ii) doing the transient simulations of a typical ungrounded microgrid under different disturbance cases, and (iii) suggesting the necessary combinations among proposed fault protection solutions of ungrounded MGs.
\end{abstract}

Key words: Fault analysis and protection, microgrid transient simulations, microgrid operation, and ungrounded microgrids.

\section{Introduction}

Microgrid technology is a main key for a development trend of smart-grids. A microgrid can operate at grid-connected and islanded modes, which contains distributed generation technologies (such as micro-turbines, fuel-cells, photovoltaic systems, etc.) in combination with energy storage devices (such as batteries, super-capacitors, and flywheels) and dispersed loads. The microgrid works in safety, stability, and reliability due to diversified protection devices, energy management systems and control strategies [1]. Distributed generators (DGs) used in a microgrid are categorized into inverter-based distributed generators (IBDGs) and rotating-based distributed generators (RBDGs) [2]. From the above categorization of DGs, an ungrounded AC microgrid is configured only if all following conditions are satisfied, including: (i) IBDGs only use 3-phase and 3-wire power converter interfaces (i.e. power converters do not use a grounded neutral wire/or their grounded fourth legs) to directly connect to the microgrid; (ii) IBDGs and RBDGs use ungrounded isolation transformers (e.g. delta/un-grounded wye transformers, un-grounded 
wye/ungrounded wye transformers) to connect to the microgrid; (iii) grid-connected transformers (or distribution transformers) placed between microgrids and the utility grids can be ungrounded or grounded at the primary side; and (iv) DGs and energy storage devices are not grounded. On the other hand, advantages of the ungrounded AC microgrids are: (i) negligible earth fault currents and (ii) operation of ungrounded microgrids is continued during ground faults (in other words, microgrid protective relays should not trip in case of the ground faults). Besides that, disadvantages of the ungrounded AC microgrids are: (i) difficulty in the earth fault protection; penetration of inverter-based DGs and rotating-based DGs into the microgrid leads to non-directional current flows; during an islanded operation mode, overcurrent relays may not be activated to protect ungrounded $\mathrm{AC}$ microgrids under the second ground faults and line-to-line faults because of fault currents limited by inverter-based DGs [3]; (ii) the second ground fault is serious; and (iii) the insulation damage can occur during single-phase to ground faults; and (iv) lightning surges cannot flow into the earth.

Relied on operation characteristics of ungrounded AC microgrids and a literature review on existing MG fault protection solutions in recent years, this paper proposes available fault protection methods for the ungrounded AC microgrids in order to solve difficulties in the earth fault protection, the second ground faults, and line-to-line faults. The proposed fault protection solutions are evaluated and analysed through results of microgrid transient simulations. Transient behaviours of a typical ungrounded AC microgrid are observed by different fault tests (e.g. line-to-ground and line-to-line faults) and microgrid operation transition tests between grid-connected and islanded operation cases. Advantages and shortcomings of each ungrounded microgrid protection solution are highlighted to figure out the effective combinations from possible fault protection solutions for the ungrounded AC microgrid protection.

\section{Available Fault Protection Methods Proposed for Ungrounded LVAC Microgrids}

\subsection{A Review on Existing Microgrid Fault Protection Methods}

Considering conventional overcurrent protection principles, conventional differential protection principles, under-voltage/over-voltage protection principles, protection principles using current and voltage sequence components, synchronisation check, and directional power-flow based protection, protective relays using the aforementioned protection principles are described in Table 1. Excepting for the protective relays mentioned in Table 1, other available fault protection solutions of AC microgrids not using the above relays are reviewed in Table 2.

Table 1. Protective Relays Are Commonly Used for LVAC Microgrids, Referred to IEEE 1547 Standard

\begin{tabular}{ll}
\hline Relays' symbol & Relay functions \\
\hline 25 & Synchronism-check relay \\
$27 / 59$ & Under/overvoltage-based protection relays \\
$27 G / 59 G$ & Neutral under/overvoltage-based protection relays \\
32 & Directional power based protection relay operates on a pre-determined value of power-flow \\
46 & Negative-phase sequence current based protection relay \\
47 & Negative-phase sequence voltage based protection relay \\
67 & Directional overcurrent relay \\
50 & Instantaneous phase overcurrent relay \\
$50 N / 51 N$ & Neutral overcurrent relays \\
$51 / 51 \mathrm{~V}$ & Time overcurrent relay/ Voltage-restrained overcurrent relay \\
37 & Under-current or under-power based protection relays \\
$81 U / O$ & Under/over-frequency based protection relays \\
$87 / 87 T$ & Differential relays/ Transformer differential relays \\
\hline \hline
\end{tabular}


Table 2. Available Fault Protection Solutions of AC Microgrids not Using Protective Relays Listed in Table 1

\begin{tabular}{ll}
\hline \hline Fault protection solutions & Detailed descriptions \\
\hline $\begin{array}{l}\text { Protection solutions use positive, negative, } \\
\text { and zero sequence components of currents }\end{array}$ & $\begin{array}{l}\text { + MG protection based on zero-sequence current and voltage components; } \\
\text { and voltages }\left(I_{\text {pos }}, I_{\text {neg }}, I_{\text {zero }}, V_{\text {pos }}, V_{\text {neg }} \text {, and } V_{\text {zero }},\right. \\
\text { respectively) [4]-[6]; }\end{array}$ \\
$\begin{array}{l}\text { current component can be used; } \\
\text { + To detect LL faults, differential protection based on the negative } \\
\text { sequence current component can be proposed; }\end{array}$
\end{tabular}

Protection solutions use d-axis and q-axis
components of current and voltage $\left(I_{d}, I_{q}, V_{d}\right.$
and $V_{q}$, respectively) in a d-q rotating
reference frame [7]-[9];

Admittance-based fault protection principle [10], [11];

Differential protection systems;

Directional overcurrent protection;
$+\mathrm{MG}$ protection operates based on comparison between d-axis and q-axis current and voltage parameters and fundamental positive-sequence current and voltage parameters in a d-q rotating coordinate system;
+ An admittance based relay is developed to protect the MG, which does not depend on limited fault current values by inverter-based distributed generators;

+ Differential energy based microgrid protection [12];

+ Impedance differential based protection scheme [13], [14];

+ A current-only directional overcurrent protection principle [15], [16];

+ An innovative directional relaying scheme based on post-fault currents this relaying scheme does not require detection of power-flow direction, in other words, there is no need for voltage and pre-fault current [17];

+ Overcurrent relay using a new time-current-voltage characteristic [18];

Total harmonic distortion (THD) of phase currents and voltages at phases $\mathrm{a}, \mathrm{b}$ and $\mathrm{c}$ $\left(T H D_{I a}, T H D_{I b}, T H D_{I c}, T H D_{V a}, T H D_{V b}\right.$, and $T H D_{V c}$, respectively) [19]-[21];

Protection schemes use wavelet transformation, travelling waves, and artificial intelligent algorithms [22]-[28];
+ Difference in the THD values of currents and voltages between normal and faulted operation modes is used to detect various faults in AC microgrids;

+ Protection based on discrete wavelet transform (DWT) multi-resolution analysis [22];

+ Using artificial neuron network based digital relays [23], [24];

+ Using fuzzy logic theory, decision tree theory, data-mining technique, etc. [25]-[28];

\footnotetext{
Adaptive protection systems (with or

without support of the communication system) [29]-[35];

Multi-agent based protection system with
support of the communication system
[36]-[43];

Wide-area protection system with support of the communication system [44]-[47];

Centralized/decentralized protection systems [32], [48], [49];

+ Use overcurrent protection principles;

+ Use over/under-voltage protection principles;

+ Use differential protection principles;

+ Use the THD values of current and voltage;
}
Protection system with use of external
devices (energy storage devices or fault + Use overcurrent protection principles; current limiters) [32], [50], [51];
Protection system using $3 I_{0}$ current and $3 V_{0}$ voltage components; with phase currents $\left(I_{a}\right.$, $\left.I_{b}, I_{c}\right)$ and voltages $\left(V_{a}, V_{b}, V_{c}\right), 3 I_{0}=I_{a}+I_{b}+I_{c}$, and $3 V_{0}=V_{a}+V_{b}+V_{c}$;
+ It is proposed to distinguish about $3 I_{0}$ and $3 V_{0}$ values between various fault situations and current and voltage unbalance cases caused by the load change in AC microgrids;

Protection system using parameters $I_{d}$ or $I_{d n}$, with $I_{d}=\left|I_{a}\right|+\left|I_{b}\right|+\left|I_{c}\right|$ and $I_{d n}=\left|I_{a}\right|+\left|I_{b}\right|+\left|I_{c}\right|+$ $\left|I_{n}\right|\left(I_{n}\right.$ is the neutral-line current) [52];

+ Difference in the values of $I_{d}$ and $I_{d n}$ between normal and faulted operation modes is used to detect various faults in AC microgrids;

\subsection{Possible Fault Protection Methods for Ungrounded Low-Voltage AC Microgrids}

A generalized fault protection structure of ungrounded low-voltage AC microgrids can be divided into six individual protection zones including: (i) protection of distributed generators and energy storage devices 
(ESSs); (ii) protection of isolation and distribution transformers; (iii) protection of power converters; (iv) protection of inverter-based DG and rotating-based DG branches; (v) protection of load branches; and (vi) protection of trunk lines and common buses. Fault protection methods proposed for each individual protection zone in an ungrounded LVAC MG are shown in Table 3.

Table 3. Possible Fault Protection Solutions for Each Different Protection Zone in an Ungrounded LVAC MG

Protection Zone 1 - Distributed Generators and Energy Storage Devices

Protection of DC distributed generators and storage devices:

In [53], fault protection solutions of DC/DC power converters and DC power sources (e.g. PV arrays, battery and super-capacitor systems) have been presented by the authors. Generally, common DC fault protection solutions are: (i) overcurrent protection (50/51), (ii) under/over-voltage protection (27/59), (iii) derivatives of current (di/dt) and voltage $(d v / d t)$, and (iv) differential protection methodology.

DC protection devices can be classified into four types, specifically: fuses, no-fuse circuit breakers, power-electronic devices, and relays.

Protection of AC distributed generators:

Common AC distributed generators are found in micro-turbine and wind-turbine generation systems. Two main types of AC generators are induction generators and synchronous generators. IEEE standard 1547 has presented typical examples for protecting synchronous and induction generators interconnected to an AC common bus [54]. Considering the ungrounded LVAC microgrids, AC distributed generators are ungrounded and connected to the microgrid through ungrounded isolation transformers. Therefore, referred to IEEE1547 Std., protective relays related to grounded neutral lines cannot be applied for the ungrounded AC microgrids.

A generalized protection system for an synchronous generator contains: (i) synchronization check (25), (ii) under-voltage (27), (iii) over-voltage (59), (iv) over-/under-frequency (810/U), (v) instantaneous overcurrent protection at phase lines (50), (vi) time overcurrent protection at phase lines (51), (vii) voltage-restrained time overcurrent (51V), (viii) power direction (32), (ix) current unbalance or negative-sequence overcurrent relay (46), (x) loss of excitation (40), (xi) differential protection (87), and (xii) directional overcurrent protection at phase lines (67).

A generalized protection scheme of an induction generator consists of: (i) under-voltage (27), (ii) over-voltage (59), (iii) negative-sequence overcurrent (46), (iv) over-/under-frequency (810/U), (v) time overcurrent protection at phase lines (51), (vi) differential protection (87), and (vii) instantaneous overcurrent protection at phase lines (50).

\section{Protection Zone 2 - Ungrounded Isolation and Distribution Transformers}

Isolation transformers are placed between DG source branches and trunk lines in an AC microgrid, while distribution transformers are placed between the AC microgrids and the utility grid.

A generalized protection system of ungrounded transformers includes: (i) time overcurrent protection at phase lines (51), (ii) instantaneous overcurrent protection at phase lines (50), (iii) under-voltage (27), (iv) over-voltage (59), and (v) differential protection (87T).

\section{Protection Zone 3 - Power Converters}

Fuses, circuit breakers, and relays can be used for the fault protection of DC/AC power inverters. When DC/AC inverters do not have the ability to limit high fault currents, fuses, circuit breakers and protective relays can effectively work to isolate the inverters from faults based on overcurrent protection principles. However, most the inverters need to limit fault currents to avoid their damage, so using relays with various operating principles will be an optimal protection solution for the DC/AC inverters.

Internal faults of inverters is mostly line-to-line faults caused by the short-circuit of switching devices. External faults of the inverters can be ground faults, line-to-line faults, and three-phase faults. Based on Table 1 and Table 2, fault protection solutions proposed for DC/AC inverters in ungrounded LVAC microgrids are: (i) under-voltage protection; (ii) under-/over-frequency protection; (iii) relays using negative-sequence current and voltage components $(46,47)$; (iv) total harmonic distortion detection of currents and voltages (THDIa, THD $I b, T H D_{I c}, T H D_{V a}, T H D_{V b}$, and $T H D_{V c}$ respectively); and (v) protective relays using $3 I_{0}$ and $3 V_{0}$ components.

\section{Protection Zone 4 - DG Source Branches}

At an islanded operation mode of ungrounded MGs: (i) under-/over-voltage protection; (ii) negative-sequence current and voltage based protection (46 and 47); (iii) total harmonic distortion detection of currents and voltages; and (iv) protective relays using $3 I_{0}$ and $3 V_{0}$ components.

At grid-connected operation mode of ungrounded MGs: (i) under-/over-voltage protection; (ii) negative-sequence current and voltage based protection (46 and 47); (iii) non-directional overcurrent protection relays $(50 / 51,51 \mathrm{~V}$ ); (iv) directional overcurrent protection relays (67); (v) total harmonic distortion detection of currents and voltages, and (vi) protective relays using $3 I_{o}$ and $3 V_{0}$ components. 


\begin{abstract}
Protection Zone 5 - Load Branches
Available fault protection solutions for load branches in ungrounded AC microgrids are: (i) instantaneous and time-delayed overcurrent protection modules along with AC circuit breakers (52); (ii) overcurrent protection relays combined with high-speed fuses; (iii) under-voltage protection (27); and (iv) negative-sequence current and voltage based protection relays (46 and 47) - in ungrounded microgrids, relays 46 and 47 are effectively used to detect ground faults with very small fault current values; and (v) total harmonic distortion detection of currents and voltages.
\end{abstract}

\begin{abstract}
Protection Zone 6 - AC Trunk Lines and Common Buses
A trunk line in an AC microgrid is defined as a line used to link two or more power sources and it does not include any load branches along its line length. In case of a multiple-microgrid system, a trunk line is understood as a line to link among individual microgrids. A common AC bus is not a trunk line only if any load branches are connected to it, so fault protection systems of trunk lines and common buses will have some noticeable differences at this situation. Fault protection schemes proposed for trunk lines and common buses in an ungrounded AC MG are mentioned as below:
\end{abstract}

Fault protection of AC trunk lines and common buses (without any connection of load branches to the common buses):

(i) Differential protection: Differential current, differential energy, and differential impedance based protection;

(ii) Directional over-current relays (67): Directional overcurrent protection principles use both current and voltage parameters; or only current [16]; or only post-fault currents and no need of voltages and pre-fault currents [17].

(iii) Differential protection based on negative-sequence current components;

(iv) Pilot relays are placed at terminals of trunk lines or common buses using various fault protection principles such as: (a) directional change of fault currents along with change in negative-sequence current and voltage values at pilot relays, (b) directional change of fault currents along with change in THD values of phase currents and voltages at pilot relays, (c) directional change of fault currents along with change in values of the ratios $\left|I_{\text {neg }}\right| /\left|I_{\text {pos }}\right|,\left(\left|I_{\text {neg }}\right|+\left|I_{\text {zero }}\right|\right) /\left|I_{\text {pos }}\right|$, $\left|V_{\text {neg }}\right| /\left|V_{\text {pos }}\right|$, or $\left(\left|V_{\text {neg }}\right|+\left|V_{\text {zero }}\right|\right) /\left|V_{\text {pos }}\right|$ at pilot relays, or (d) directional change of fault currents along with change in values of $I_{d}\left(I_{d}=\left|I_{a}\right|+\left|I_{b}\right|+\left|I_{c}\right|\right), V_{a}, V_{b}$ and $V_{c}$ at pilot relays [52].

(v) Admittance based protection principles;

Fault protection of AC common buses (with load branches connected to the common buses):

When load branches are connected to an AC common bus and a fault occurs at this common bus, it is impossible to detect a directional change of currents before and after the fault. As a result, pilot relays which use different fault protection principles as mentioned in case of no load branches connected to the common bus, cannot be used to detect the faults. Similarly, use of differential relays is also ineffective. Thus, only some following protection solutions are adaptable to solve the above problem, including:

(i) Directional over-current relays;

(ii) Admittance based protection relay;

\title{
3. Evaluating Critical Fault Protection Solutions of Ungrounded LVAC Microgrids Based on Transient Simulation Results
}

Transient simulation results of a typical ungrounded LVAC microgrid are used to evaluate fault protection methods proposed for each different protection zone in an ungrounded LVAC microgrid. A typical ungrounded AC microgrid is indicated in Fig. 1. This microgrid has a 20.16kW PV generation system, a $100 \mathrm{kWh}$ battery power conditioning system, and a $65 \mathrm{~kW}$ gas micro-turbine system. This is an actual LVAC microgrid test-bed built at Institute of Nuclear Energy Research, Taiwan. All neutral points of isolation transformers, distribution transformer, and distributed generators are isolated from the ground to configure a low-voltage AC ungrounded MG.

Considering fault protection solutions suggested for DC and AC distributed generators, energy storage devices (ESSs), and ungrounded isolation and distribution transformers as mentioned at Table 3, these solutions use mostly protective relays listed in Table 1. In addition to, IEEE 1547.2-2008 standard also guides combinations of protective relays mentioned in Table 1 in order to protect DGs and transformers. Therefore, this paper ignores evaluation of fault protection methods of DGs, ESSs, and transformers in ungrounded LVAC microgrids. Moreover, fault protection of load branches is unnecessary to be evaluated because using common protective relays listed in Table 1 is very effectively to protect the load branches in MGs [29]-[35]. From above reasons, only protection solutions proposed for inverters, DG source branches, 
trunk lines, and common buses will be evaluated in details.

Transient behaviours of an ungrounded LVAC microgrid are surveyed through single-line to ground (SLG) fault and line-to-line (LL) fault tests at three different locations, namely, at an AC trunk line - $\mathrm{F}_{2}$ location, at an AC common bus - $\mathrm{F}_{3-1}$ location, and at output of a DC/AC inverter at a PV branch - $\mathrm{F}_{3-2}$ location; and microgrid operation transition test from an islanded mode into a grid-connected mode. In relation to operation of an ungrounded microgrid simulation model, a PV system, a battery system, and a micro-turbine system operate at an islanded mode from 0 s to $60 \mathrm{~s}$, and they are connected to the utility grid after the $60^{\text {th }}$ second. Starting time of the micro-turbine system is about $40 \mathrm{~s}$, so it is interconnected to the $\mathrm{PV}$ and battery systems from the $45^{\text {th }}$ second. After 60 s, the micro-turbine system will be synchronized to the utility grid along with the PV and battery systems. SLG and LL faults are assumed to occur at the $10^{\text {th }}$, $50^{\text {th }}$ and $62^{\text {nd }}$ seconds in a simulated ungrounded AC microgrid. Operation transition test of an ungrounded MG from the islanded mode into the grid-connected mode is simulated at the $60^{\text {th }}$ second. For a fault location $\mathrm{F}_{2}$, two microgrid digital relays (MDR), MDR6 and MDR7, will measure fault parameters, refer to Fig. 1. For a fault location $\mathrm{F}_{3-1}$, MDR4, MDR5\&MDR7 are activated. For a fault location $\mathrm{F}_{3-2}$, MDR4 are activated to protect a PV branch.

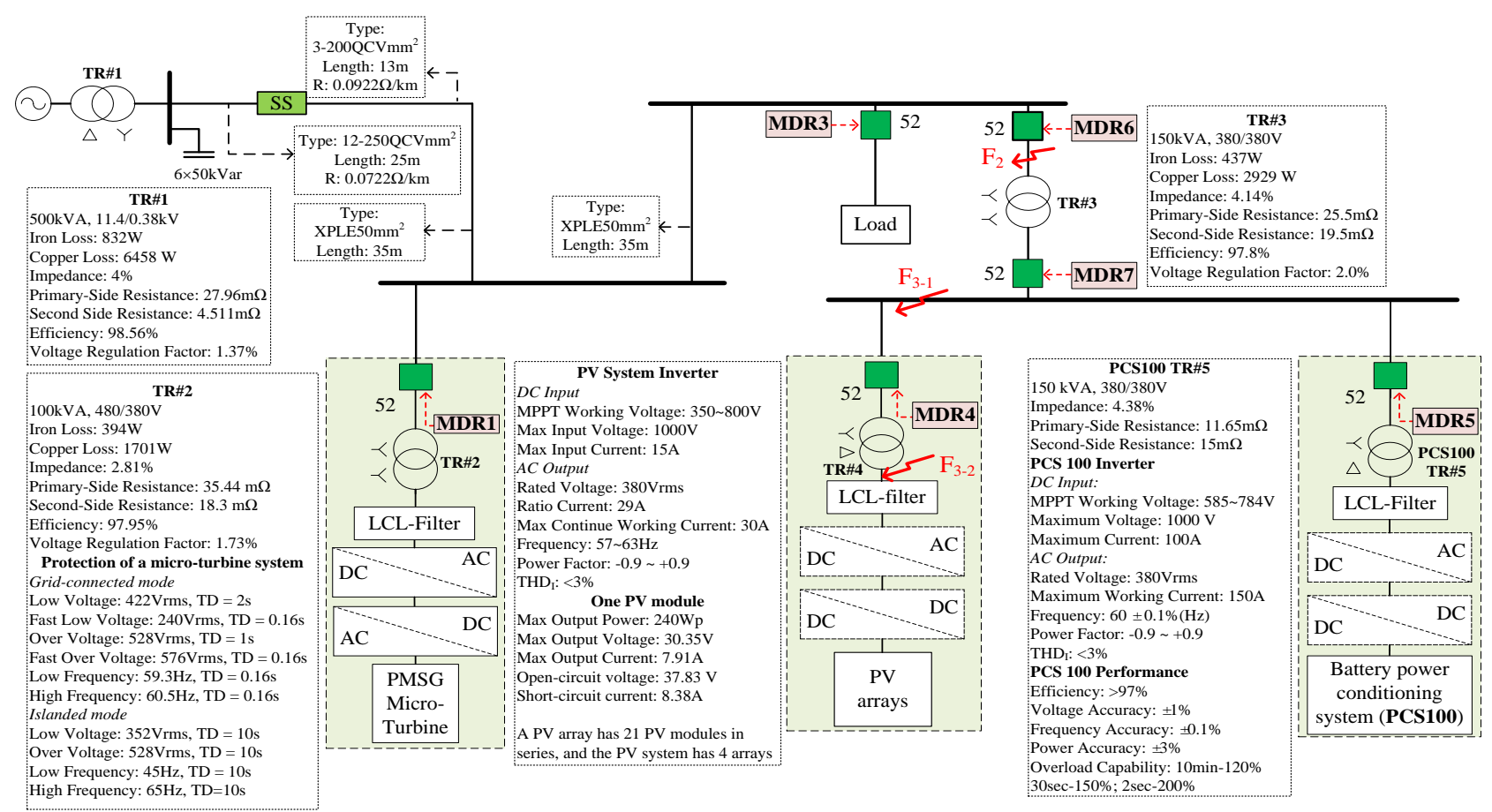

Fig. 1. A low-voltage AC microgrid test-bed with ungrounded isolation and distribution transformers and ungrounded DGs and ESSs is used to simulate in PSCAD.

\subsection{Transient Simulation Results of Single-Line to Ground Faults at $F_{2}, F_{3-1}$, and $F_{3-2}$}

For a SLG fault occurring at a location $\mathrm{F}_{2}$ (i.e. the location of an AC trunk line in an ungrounded microgrid), MDR6 and MDR7 will observe positive, negative and zero sequence currents and voltages ( $I_{\text {pos }}, I_{\text {neg, }}, I_{\text {zero }}$ and $V_{\text {pos }}, V_{\text {neg }}, V_{\text {zero }}$, respectively), ratios of $\left|I_{\text {neg }}\right| /\left|I_{\text {pos }}\right|,\left|I_{\text {zero }}\right| /\left|I_{\text {pos }}\right|,\left(\left|I_{\text {neg }}\right|+\left|I_{\text {zero }}\right|\right) /\left|I_{\text {pos }}\right|,\left|V_{\text {neg }}\right| /\left|V_{\text {pos }}\right|,\left|V_{\text {zero }}\right| /\left|V_{\text {pos }}\right|$, and $\left(\left|V_{\text {neg }}\right|+\left|V_{\text {zero }}\right|\right) /\left|V_{\text {pos }}\right|$, total harmonic distortion of currents and voltages at each phase $\mathrm{a}, \mathrm{b}$ and c $\left(T H D_{I a}, T H D_{I b}\right.$, $T H D_{I c}, T H D_{V a}, T H D_{V b}$, and $\left.T H D_{V c}\right)$, and three-phase fault currents and voltages $\left(I_{a}, I_{b}, I_{c}, V_{a}, V_{b}\right.$, and $\left.V_{c}\right)$, as shown in Fig. 2 and Fig. 3. SLG fault inception time is at the $50^{\text {th }}$ and $62^{\text {nd }}$ seconds. The SLG fault time is 0.1s. At the $50^{\text {th }}$ second, micro-turbine, PV, and battery systems are operating at an islanded mode. The battery 
system is fully charged. Total load power in a simulated ungrounded microgrid is $45 \mathrm{~kW}$. On the other hand, at the $62^{\text {nd }}$ second, micro-turbine, PV, and battery systems are connected to the utility grid.

For a SLG fault occurring at a location $\mathrm{F}_{3-1}$ (i.e. location at a AC common bus), MDR4, MDR5, and MDR7 will observe positive, negative, and zero sequence currents and voltages, ratios of $\left|I_{\text {neg }}\right| /\left|I_{\text {pos }}\right|,\left|I_{\text {zero }}\right| /\left|I_{\text {pos }}\right|$, $\left(\left|I_{\text {neg }}\right|+\left|I_{\text {zero }}\right|\right) /\left|I_{\text {pos }}\right|,\left|V_{\text {neg }}\right| /\left|V_{\text {pos }}\right|,\left|V_{\text {zero }}\right| /\left|V_{\text {pos }}\right|$, and $\left(\left|V_{\text {neg }}\right|+\left|V_{\text {zero }}\right|\right) /\left|V_{\text {pos }}\right|$, THD of currents and voltages, and three-phase fault currents and voltages, as indicated in Fig. 4. The SLG fault occurs at the $50^{\text {th }}$ second and the fault time is $0.1 \mathrm{~s}$. For a SLG fault occurring at a location $\mathrm{F}_{3-2}$ (i.e. location at a DG source branch), fault parameters are measured at MDR4 and PV inverter's output, as seen in Fig. 5, Fig. 6, and Fig. 7. The SLG fault occurs at the $10^{\text {th }}, 50^{\text {th }}$, and $62^{\text {nd }}$ seconds and the fault time is $0.1 \mathrm{~s}$. It is noted that at the $10^{\text {th }}$ second, a battery system is being charged by a $20.16 \mathrm{~kW}$ PV generation system and an $18 \mathrm{~kW}$ resistive load is connected to the simulated microgrid.

Considering SLG fault simulation results at $\mathrm{F}_{2}$ (phase $a$ is a faulted phase) occurring at the $50^{\text {th }}$ and $62^{\text {nd }}$ seconds: MDR6 and MDR7 can use parameters $I_{\text {neg, }} V_{\text {neg, }},\left|I_{\text {neg }}\right| /\left|I_{\text {pos }}\right|, \quad\left(\left|I_{\text {neg }}\right|+\left|I_{\text {zero }}\right|\right) /\left|I_{\text {pos }}\right|,\left|V_{\text {neg }}\right| /\left|V_{\text {pos }}\right|$, $\left(\left|V_{\text {neg }}\right|+\left|V_{\text {zero }}\right|\right) /\left|V_{\text {pos }}\right| T H D_{I a}$ and $T H D_{V a}$ to exactly detect a SLG fault because values of these parameters increase suddenly when the SLG fault occurs at $F_{2}$, referred to Fig. 2 and Fig. 3. Values of the above parameters at a faulted situation are many times higher than those at a normal operation mode of a simulated ungrounded microgrid. At the $62^{\text {nd }}$ second, a fault current value measured at MDR6 is the sum of partial fault currents from a micro-turbine system and from the grid. In Fig. 2(b), phase fault currents measured at PV and battery branches are limited to 2.0pu because they are connected to the microgrid through power-converter interfaces. In Fig. 3, THD of the fault current measured at MDR6 at the $62^{\text {nd }}$ second is high at 70\%, while THD of the operating current observed at MDR6 before the $62^{\text {nd }}$ second is about $30 \%$. High THD of the operating current at 30\% can be caused by neutral point shift of voltage and current in the ungrounded microgrid, which can lead to false tripping of MDR6 when the ungrounded microgrid is normally operating at a grid-connected mode.

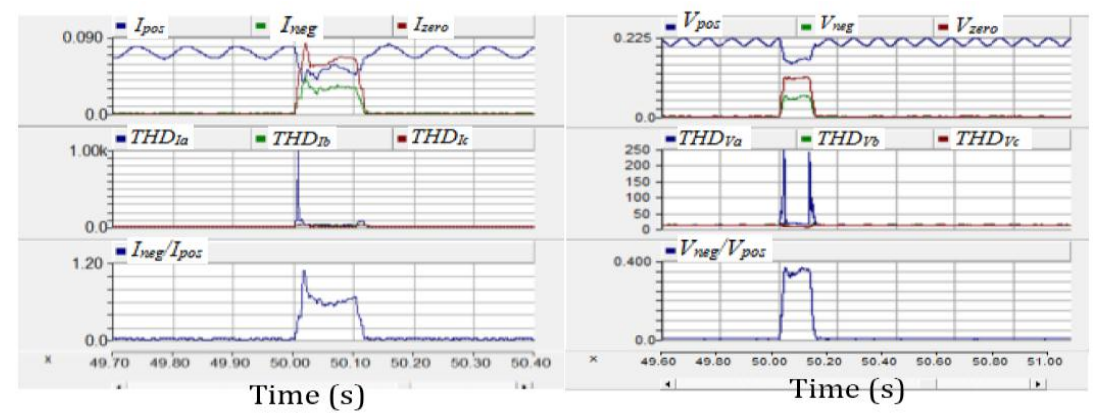

(a) Various parameters measured by MDR6 for a SLG fault at the $50^{\text {th }}$ second.
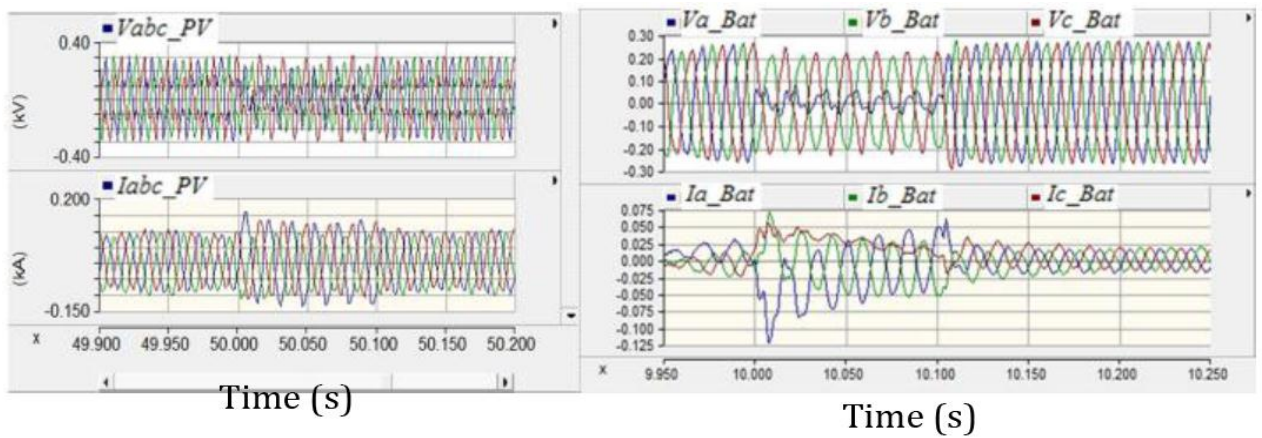

(b) PV current and voltage parameters $\left(V_{a b c_{-} P V}\right.$ and $\left.I_{a b c_{-} P V}\right)$ and output voltages and currents of the battery $\operatorname{system}\left(V_{a_{-} B a t}, V_{b_{-} B a t}, V_{c_{-} B a t}, I_{a_{-} B a t}, I_{b_{-} B a t}, I_{C_{-} B a t}\right)$. 


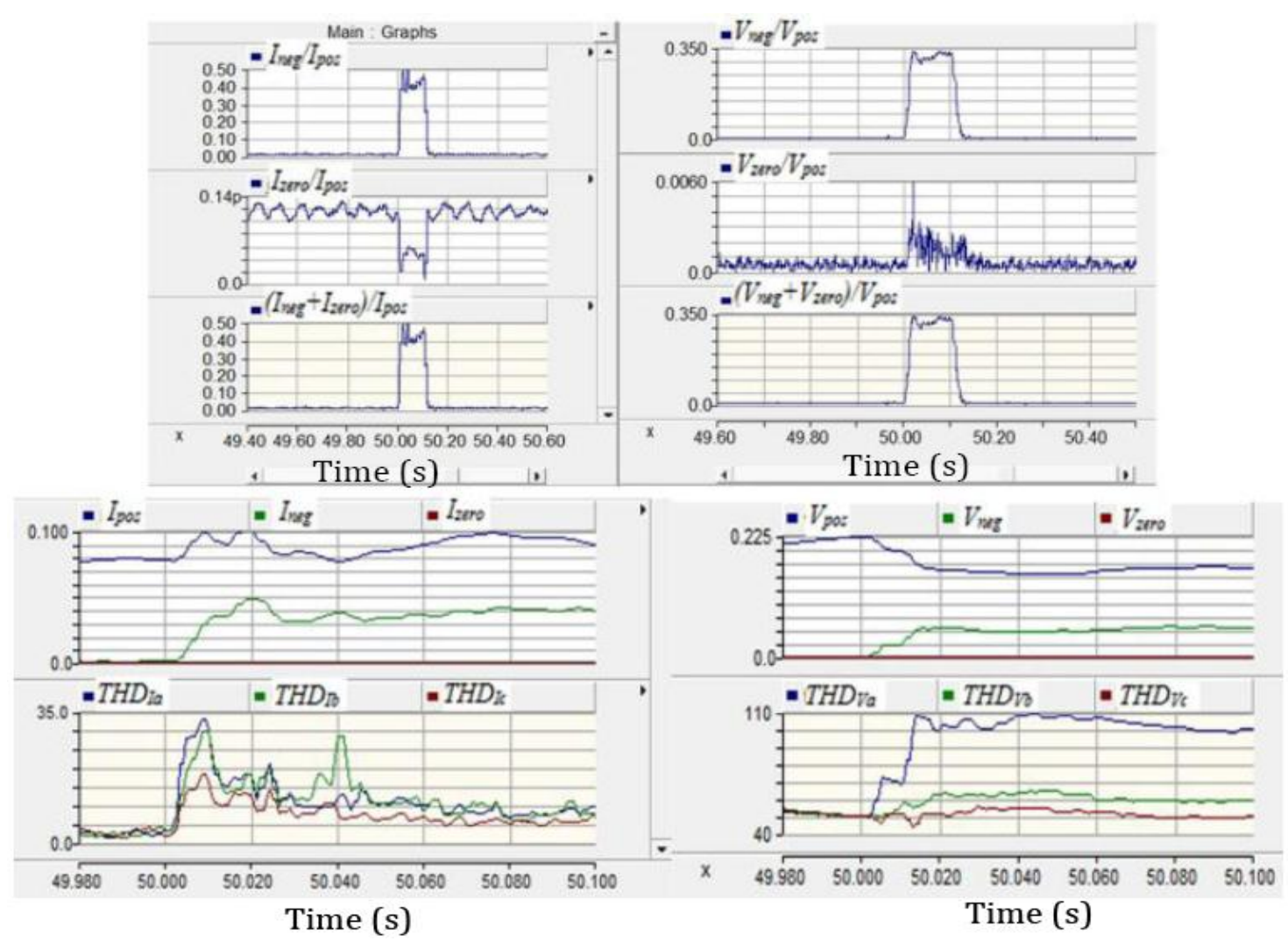

(c) Various parameters measured by MDR7 for a SLG fault at the $50^{\text {th }}$ second.

Fig. 2. Fault parameters observed at MDR6 and MDR7 at the $50^{\text {th }}$ second.
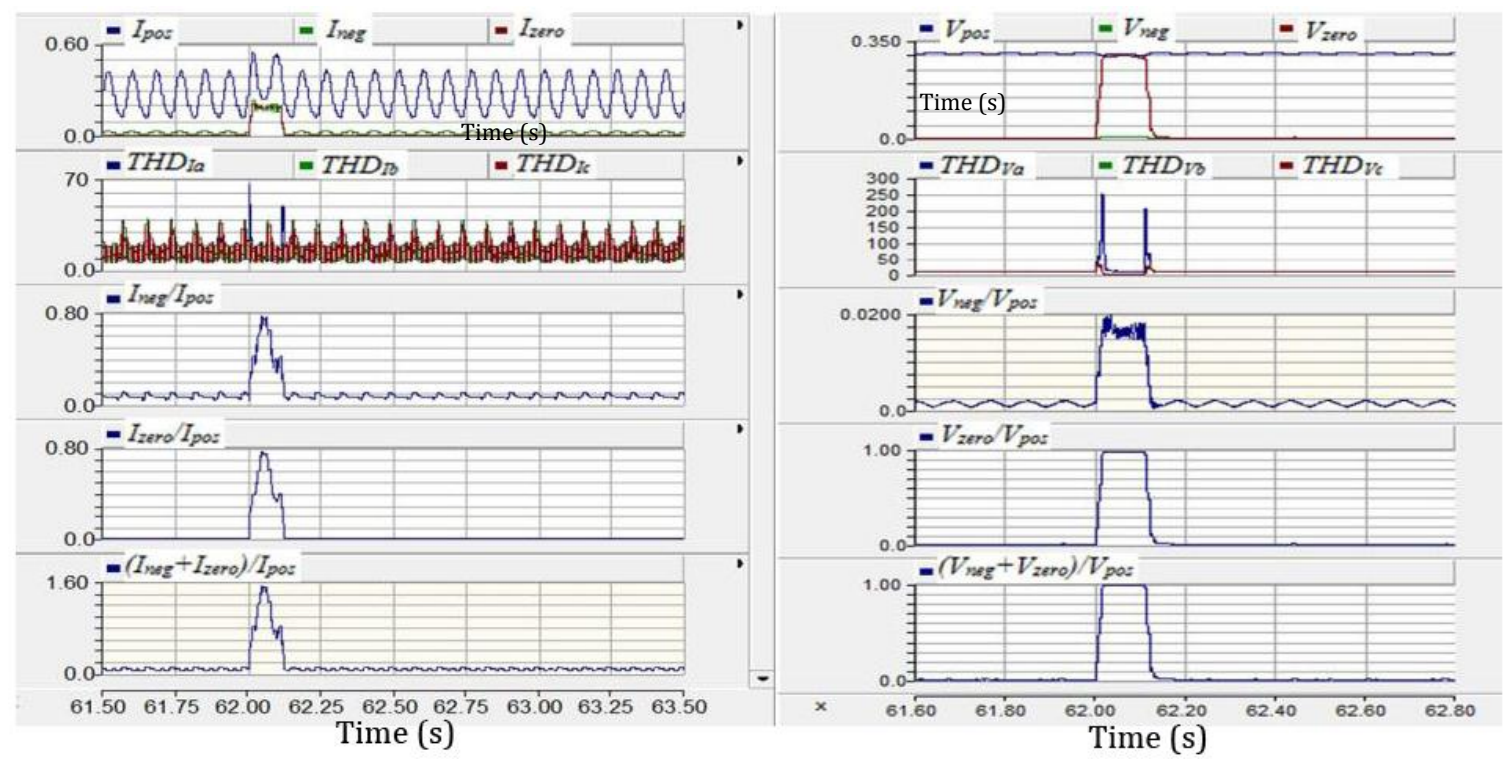

Fig. 3. Fault parameters observed at MDR6, at the $62^{\text {nd }}$ second, and at the $F_{2}$ location.

Considering SLG fault simulation results at $\mathrm{F}_{3-1}$ (phase $a$ is a faulted phase) at the $50^{\text {th }}$ second: MDR7 measures a fault current flowing from a micro-turbine source branch to location $\mathrm{F}_{3-1}$. Fig. 4(b) shows that two parameters of positive sequence current and voltage measured at MDR7 cannot be used to detect a SLG fault at $F_{3-1}$ because their values insignificantly change when the fault occurs. In Fig. 4(c), direction of fault currents observed at MDR4 and MDR5 is opposite to that observed at MDR7. MDR4 and MDR5 measure currents and voltages of PV and battery branches, respectively, while MDR7 measures currents and voltages 
at the micro-turbine branch. Fault currents at the PV, battery, and micro-turbine source branches are limited to less than 2.0pu. Besides that, because of a neutral point shift in the ungrounded MG, output fault currents at the PV and battery systems have a DC-offset level. Values of parameters $I_{\text {neg, }}, V_{\text {neg, }}\left|I_{\text {neg }}\right| / \mid I_{\text {pos }}$, $\left(\left|I_{\text {neg }}\right|+\left|I_{\text {zero }}\right|\right) /\left|I_{\text {pos }}\right|,\left|V_{\text {neg }}\right| /\left|V_{\text {pos }},\left(\left|V_{\text {neg }}\right|+\left|V_{\text {zero }}\right|\right) /\right| V_{\text {pos }} \mid, T H D_{\text {Ia }}$ and $T H D_{V a}$ are very high during the fault time.

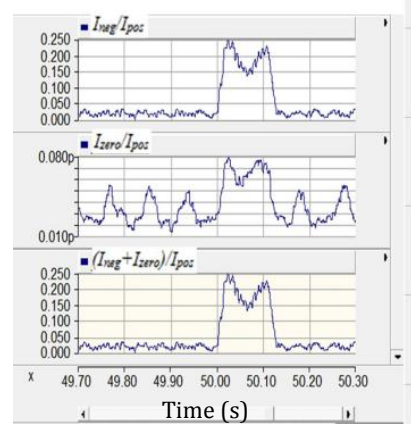

(a) Fault parameters measured at MDR4 for a SLG fault at $\mathrm{F}_{3-1}$.

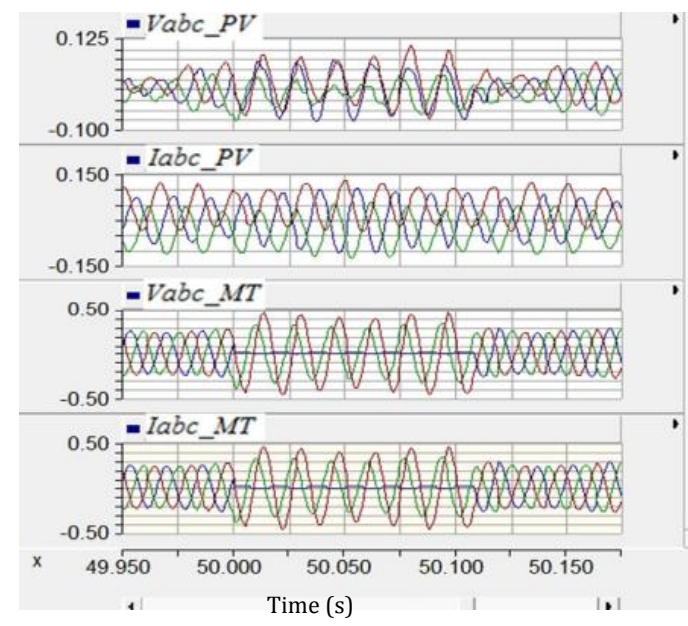

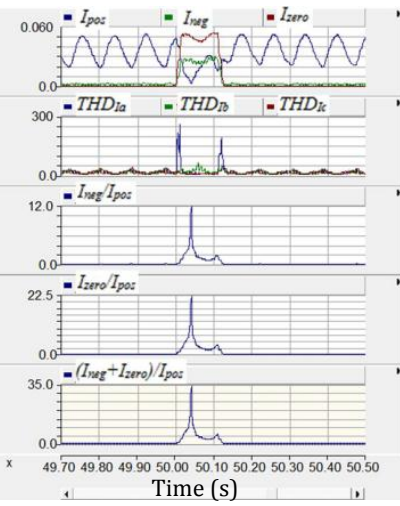

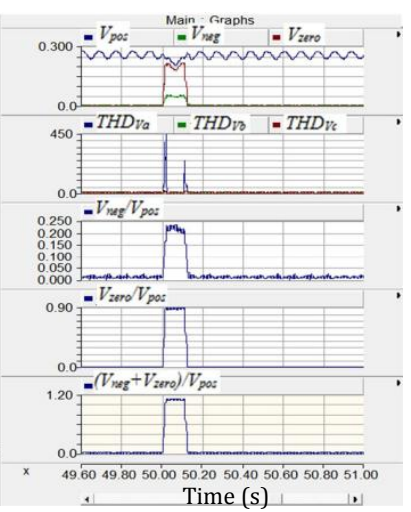

(b) Fault parameters measured at MDR7 for a SLG fault at $\mathrm{F}_{3-1}$.

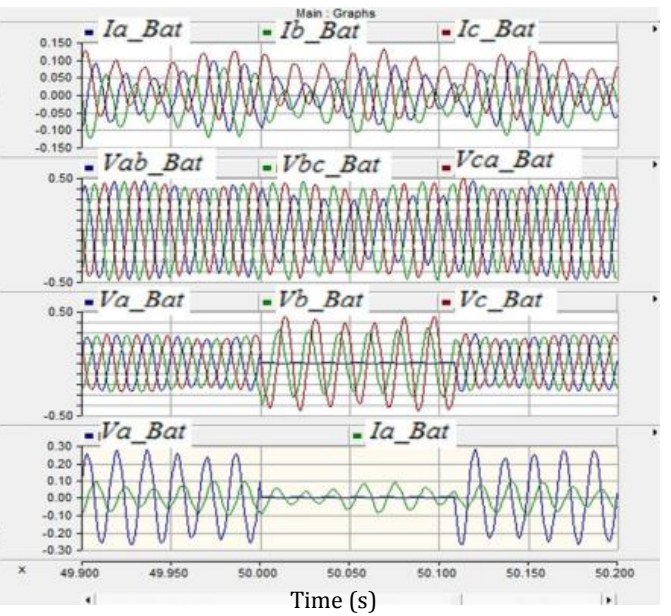

MDR7, and MDR5.

Fig. 4. Fault parameters observed at MDR4, MDR5, \& MDR7 for a SLG fault at $\mathrm{F}_{3-1}$ at the $50^{\text {th }}$ second in a simulated ungrounded MG.

Considering transient simulation results of a SLG fault at $\mathrm{F}_{3-2}$ (phase $a$ is a faulted phase): MDR4 is installed to protect a PV source branch when a SLG fault $F_{3-2}$ occurs at the $10^{\text {th }}$ second. MDR4 measures a fault current flowing from a battery storage system to $\mathrm{F}_{3-2}$. PV inverter's output measures a fault current produced by PV arrays as shown in Fig. 5. Fault protection solutions for PV inverters are ineffective in case of using zero-sequence current $I_{\text {zero }}$ and a ratio $\left|I_{\text {zero }}\right| /\left|I_{\text {pos }}\right|$ because their values during the fault time (duration of $0.1 \mathrm{~s}$ from the $10^{\text {th }}$ second) negligibly change when compared to their values at a normal operation mode of an ungrounded microgrid. Remaining parameters such as $I_{\text {pos }}, I_{\text {neg }}, V_{\text {pos }}, V_{\text {neg }},\left|I_{\text {neg }}\right| /\left|I_{\text {pos }}\right|$, $\left(\left|I_{\text {neg }}\right|+\left|I_{\text {zero }}\right|\right) /\left|I_{\text {pos }}\right|,\left|V_{\text {neg }}\right| /\left|V_{\text {pos }},,\left(\left|V_{\text {neg }}\right|+\left|V_{\text {zero }}\right|\right) /\right| V_{\text {pos }} \mid, T H D_{\text {Ia }}$, or $T H D_{V a}$ can be applied for SLG fault protection solutions of PV inverters in the PV source branch, refer to Fig. 5. When the SLG fault $\mathrm{F}_{3-2}$ occurs at the $50^{\text {th }}$ second, MDR4 placed at terminal of the PV branch observes fault currents flowing from micro-turbine and battery systems to a faulty location $\mathrm{F}_{3-2}$. Fault current directions observed at MDR4 and the PV inverter's output are opposite to each other, refer to Fig. 6(b). Besides that, Fig. 6(a) indicates that MDR4 cannot use zero-sequence current $I_{\text {zero }}$ and a ratio $\left|I_{\text {zero }}\right| /\left|I_{\text {pos }}\right|$ to detect the SLG fault $\mathrm{F}_{3-2}$ at the $50^{\text {th }}$ second because 
difference in their values between normal operation and faulted modes is insignificant. For a SLG fault $\mathrm{F}_{3-2}$ occurring at the $62^{\text {nd }}$ second, an ungrounded LVAC microgrid is connected to the utility grid, so total fault current flowing from the grid, micro-turbine and battery systems is observed at MDR4, see Fig. 7. Two parameters $I_{\text {zero }}$ and $\left|I_{\text {zero }}\right| /\left|I_{\text {pos }}\right|$ cannot be used for the SLG fault detection at the PV branch.
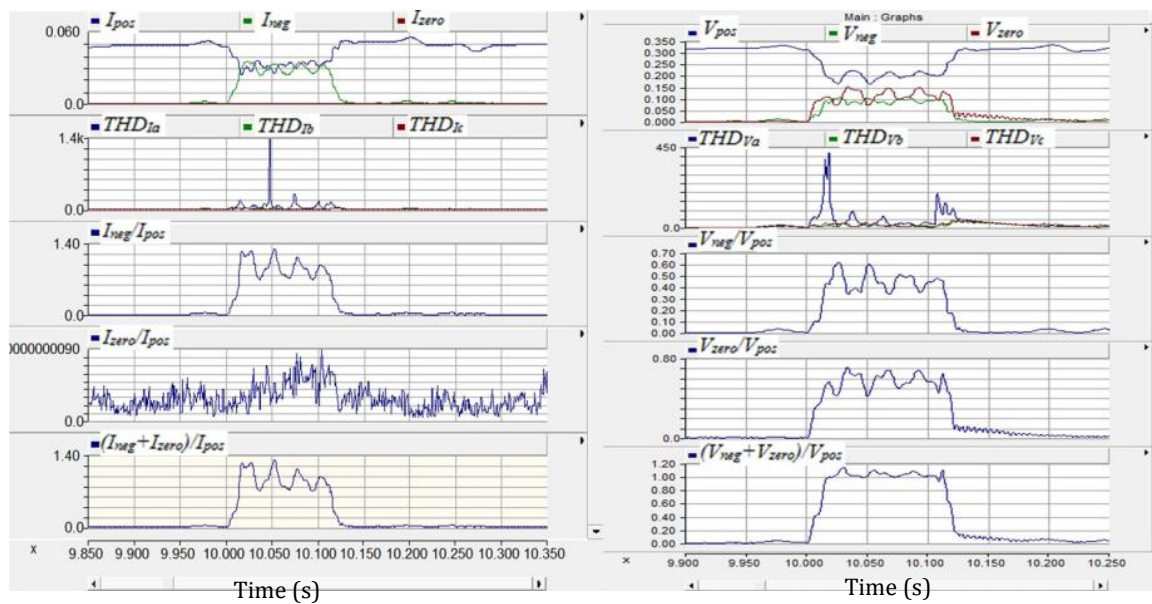

Fig. 5. Fault parameters are observed at PV inverter's output in the PV branch with respect to a SLG fault $F_{3-2}$ occurring at the $10^{\text {th }}$ second.

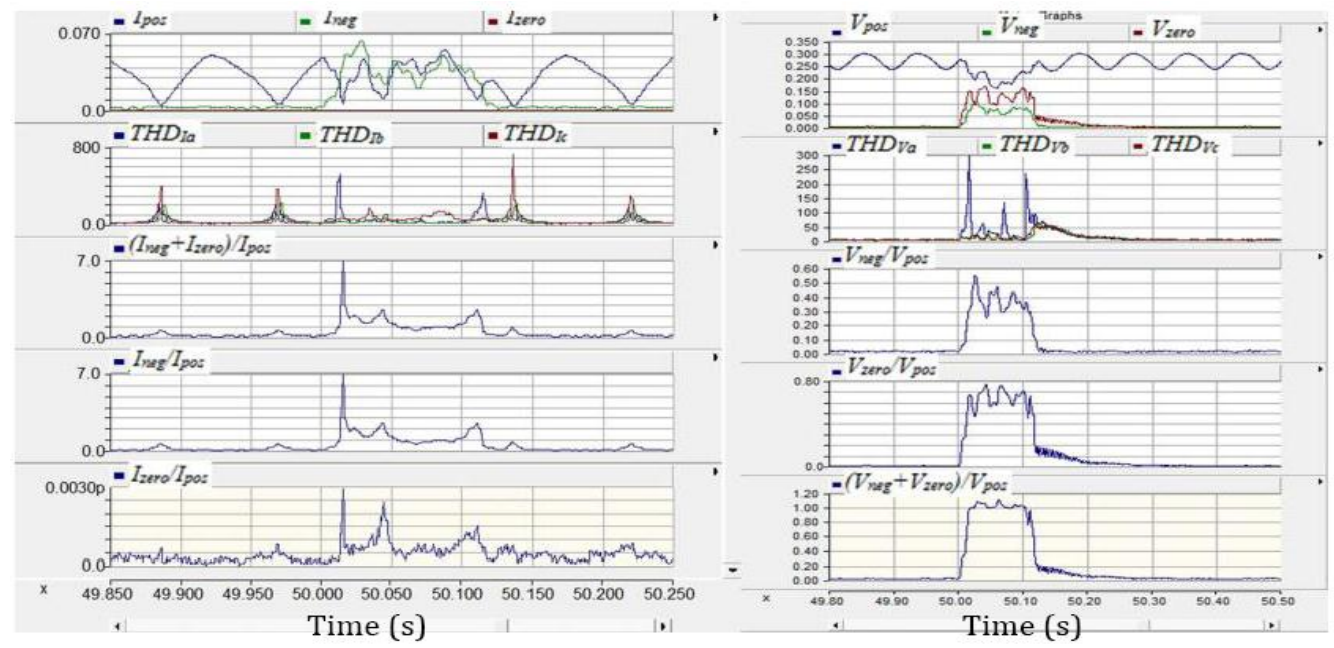

(a) Parameters measured at MDR4 for a SLG fault $\mathrm{F}_{3-2}$ at the $50^{\text {th }}$ second.

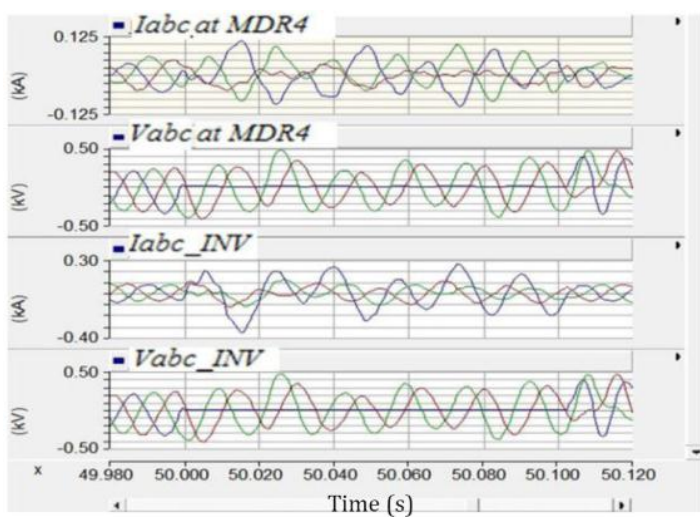

(b) Phase fault currents and voltages measured at MDR4 and the PV inverter's output ( $I_{a b c_{-} I N V}$ and $\left.V_{a b c_{-} I N V}\right)$ in the PV branch.

Fig. 6. Simulation results of a SLG fault $\mathrm{F}_{3-2}$ occurring at the $50^{\text {th }}$ second. 

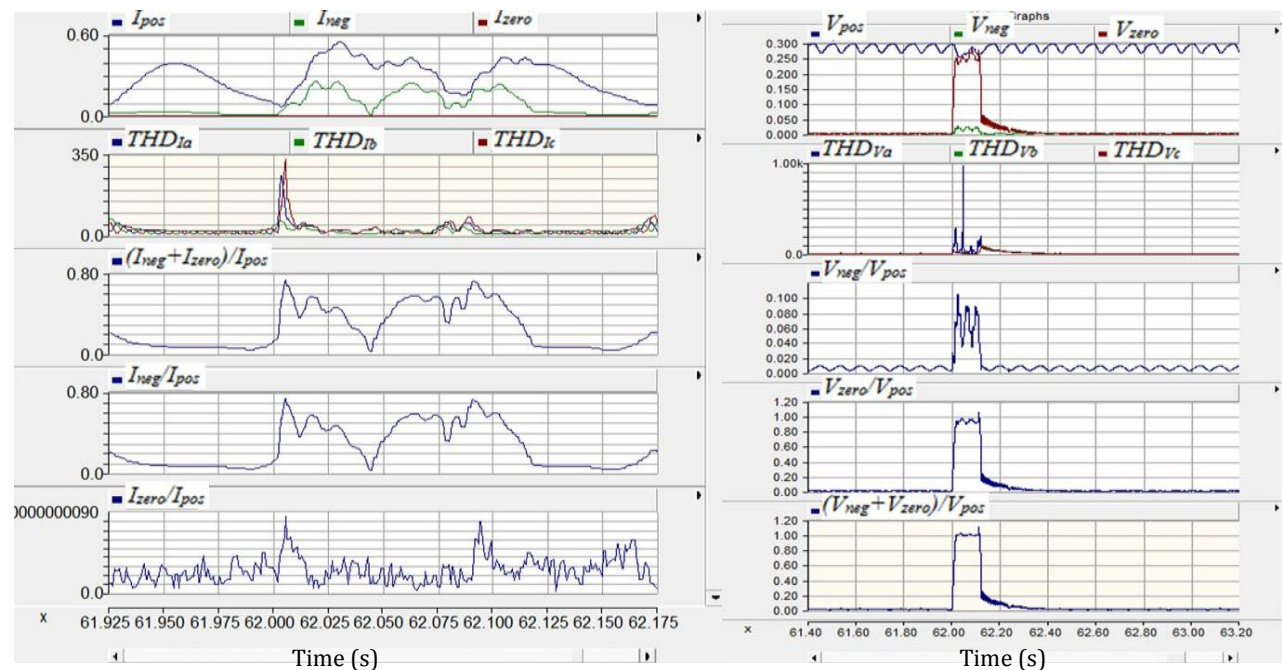

Fig. 7. Fault parameters are observed at MDR4 for the SLG fault $\mathrm{F}_{3-2}$ occurring at the $62^{\text {nd }}$ second.

\subsection{Transient Simulation Results of Line-to-Line Faults at $F_{2}, F_{3-1}$, and $F_{3-2}$ Locations}
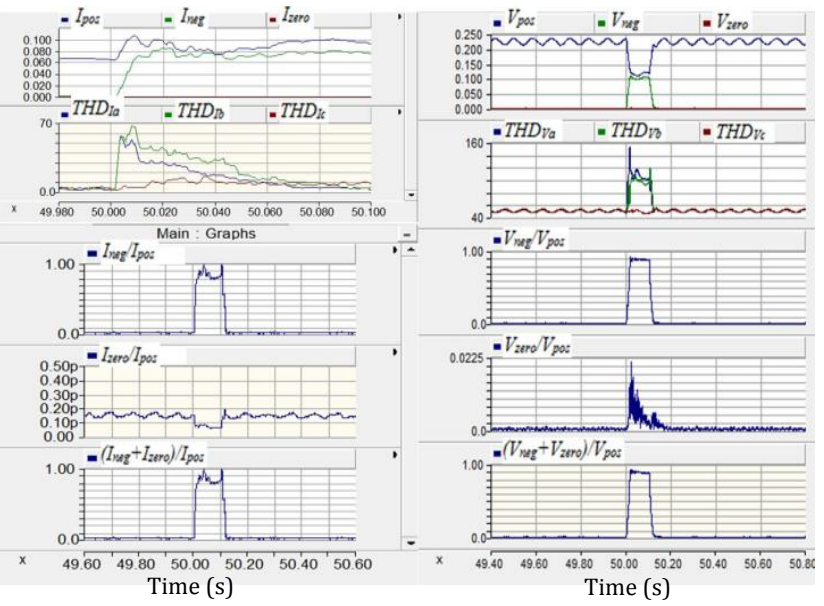

(a) Parameters measured at MDR7 for a line-to-line fault $\mathrm{F}_{2}$ at the $50^{\text {th }}$ second.
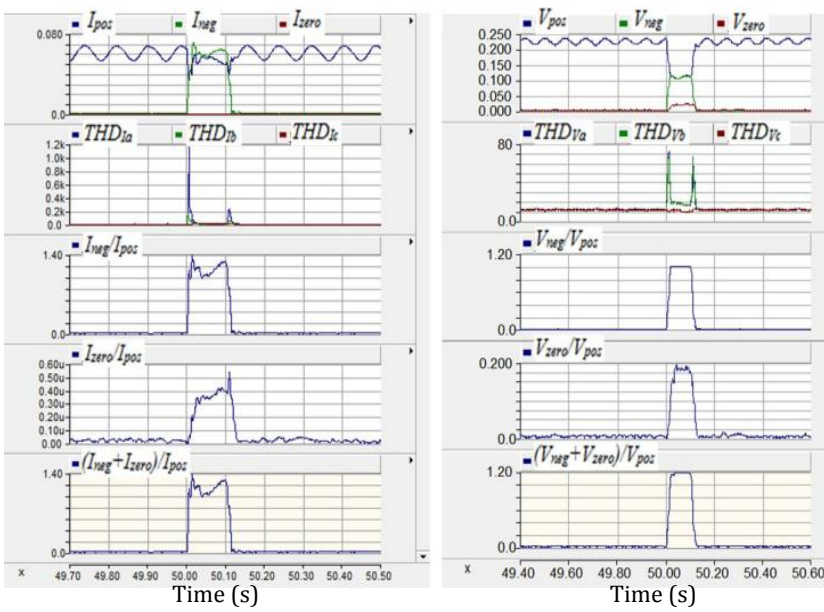

(b) Parameters measured at MDR6 for a line-to-line fault $\mathrm{F}_{2}$ at the $50^{\text {th }}$ second.
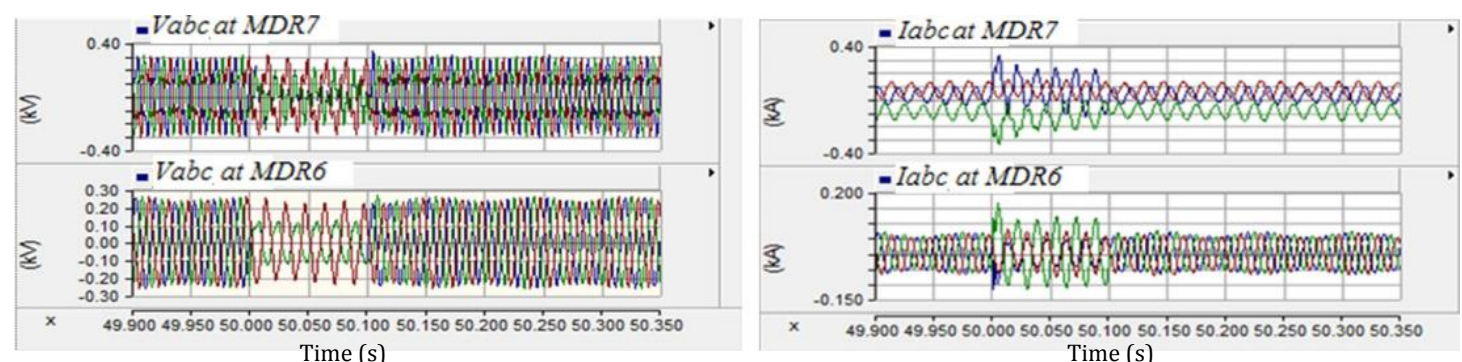

(c) Phase fault currents and voltages measured at MDR7 and MDR6.

Fig. 8. Fault parameters observed at MDR6 \& MDR7 with respect to a LL fault $F_{2}$ at the $50^{\text {th }}$ second.

Considering a line-to-line (LL) fault occurring at an AC trunk line (a $\mathrm{F}_{2}$ location as indicated in Fig. 1) in a simulated ungrounded LVAC microgrid, fault parameters are observed at MDR6 and MDR7 as shown in Fig. 8 and Fig. 9. The LL fault occurs at the $50^{\text {th }}$ and $62^{\text {nd }}$ seconds. Based on transient simulation results of a LL fault at $\mathrm{F}_{2}$, main conclusions are given as the following: (i) parameters $I_{\text {zero }}, V_{\text {zero }},\left|I_{\text {zero }}\right| /\left|I_{\text {pos }}\right|$ and $\left|V_{\text {zero }}\right| /\left|V_{\text {pos }}\right|$ cannot be applied for LL fault protection solutions. Otherwise, other parameters such as $I_{\text {neg, }}, V_{\text {neg, }},\left|I_{\text {neg }}\right| /\left|I_{\text {pos }}\right|$, $\left(\left|I_{\text {neg }}\right|+\left|I_{\text {zero }}\right|\right) /\left|I_{\text {pos }}\right|,\left|V_{\text {neg }}\right| /\left|V_{\text {pos }}\right|,\left(\left|V_{\text {neg }}\right|+\left|V_{\text {zero }}\right|\right) / \mid V_{\text {pos }}, T H D_{\text {Ia }}, T H D_{I b}, T H D_{V a}$ and $T H D_{V b}$ can be effectively applied to 
detect the LL fault at $\mathrm{F}_{2}$; (ii) THD of phase currents is quite high at a grid-connected operation mode of the ungrounded microgrid, see Fig. 9(b). One of reasons can be non-synchronization of neutral points between the ungrounded microgrid and the utility (in other words, a problem of neutral point shift in the ungrounded microgrid); (iii) a LL fault voltage drops to $50 \%$ of a rated voltage value; (iv) DC-offset components exist in the operating and fault currents of a simulated ungrounded MG because of a neutral point shift, see Fig. 8(c). Therefore, it is necessary to solve this problem in real-time ungrounded LVAC microgrids in order to restrict mal-operation of fault protection systems; and (v) THD values of phase fault currents and voltages are very high at fault inception times (at the $50^{\text {th }}$ and $62^{\text {nd }}$ seconds).

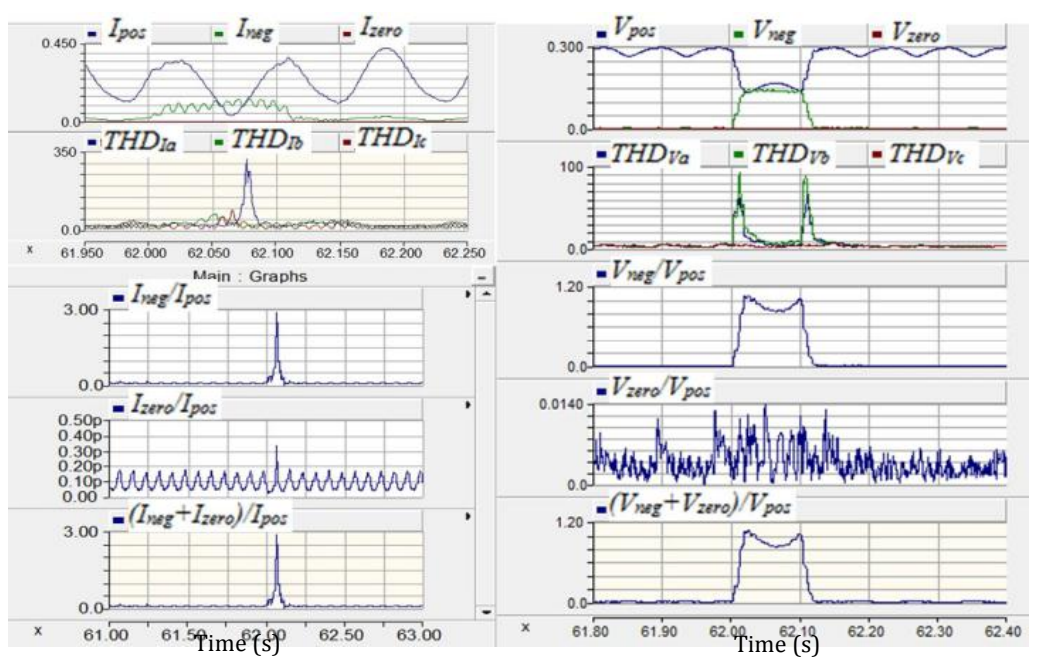

(a) Parameters measured at MDR7 for a line-to-line fault $\mathrm{F}_{2}$ at the $62^{\text {nd }}$ second.
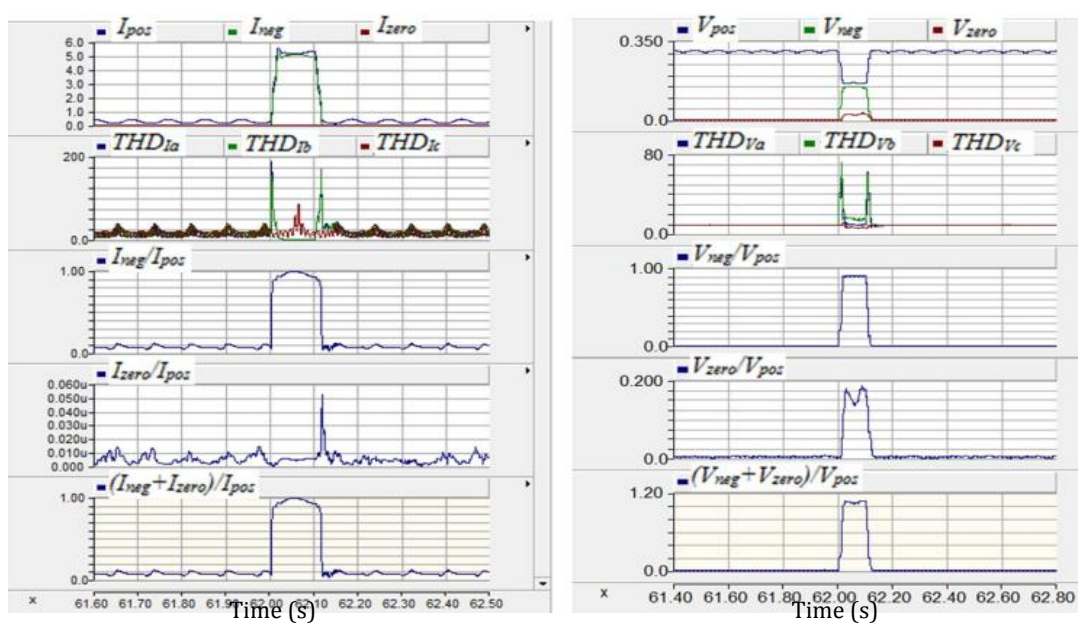

(b) Parameters measured at MDR6 for a line-to-line fault $F_{2}$ at the $62^{\text {nd }}$ second.

Fig. 9. Fault parameters observed at MDR6 \& MDR7 with respect to a LL fault $F_{2}$ at the $62^{\text {nd }}$ second.

Considering a LL fault occurring at an AC common bus - a $\mathrm{F}_{3-1}$ location, MDR4, MDR5, and MDR7 should be activated to isolate this LL fault. Because a faulty common bus ( $\left.\mathrm{F}_{3-1}\right)$ does not contain any load branch (referred to Fig. 1), LL fault behaviours at the $\mathrm{F}_{3-1}$ location are similar to LL fault behaviours at the location $\mathrm{F}_{2}$ - a trunk line. In particular, parameters $I_{\text {zero }}, V_{\text {zero }},\left|I_{\text {zero }}\right| /\left|I_{\text {pos }}\right|$ and $\left|V_{\text {zero }}\right| /\left|V_{\text {pos }}\right|$ cannot be used for line-to-line fault detection at the $\mathrm{F}_{3-1}$ location, otherwise, other parameters such as $I_{\text {neg, }}, V_{\text {neg, }},\left|I_{\text {neg }}\right| /\left|I_{\text {pos }}\right|,\left(\left|I_{\text {neg }}\right|+\left|I_{\text {zero }}\right|\right) /\left|I_{\text {pos }}\right|$, $\left|V_{\text {neg }}\right| /\left|V_{\text {pos }}\right|,\left(\left|V_{\text {neg }}\right|+\left|V_{\text {zero }}\right|\right) /\left|V_{\text {pos }}\right|, T H D_{I a}, T H D_{I b}, T H D_{V a}$ and $T H D_{V b}$ can be effectively used. The LL fault $\mathrm{F}_{3-1}$ happens at the $50^{\text {th }}$ second, meanwhile, a battery energy storage system is fully charged by PV and micro-turbine systems. Therefore, the battery storage system immediately discharges to the MG in order to maintain the MG operating voltage. Consequently, fault voltages are not reduced to zero. Fault currents of PV, 
battery, and micro-turbine systems are less than 2.0pu due to fault current limitation ability of DC/AC power inverters.

Considering a LL fault occurring at a PV source branch $\left(\mathrm{F}_{3-2}\right)$, Fig. 10 and Fig. 11 describe fault parameters that are observed at MDR4 and the PV inverter's output. The line-to-line fault $\mathrm{F}_{3-2}$ occurs at the $10^{\text {th }}$ and $50^{\text {th }}$ seconds and is cleared after $0.1 \mathrm{~s}$. Based on transient simulation results, parameters $I_{\text {zero }}, V_{\text {zeroo }},\left|I_{\text {zero }}\right| /\left|I_{\text {pos }}\right|$, and $\left|V_{\text {zero }}\right| /\left|V_{\text {pos }}\right|$ cannot be used for LL fault detection. DC-offset components appear at phase currents of a battery source branch when the LL fault occurs (see Fig. 10(a)). After the fault is cleared, it spends a short-time period for the phase currents to recover their normal waveforms. Depending on a time constant, the DC-offset current components are decayed quickly or slowly.

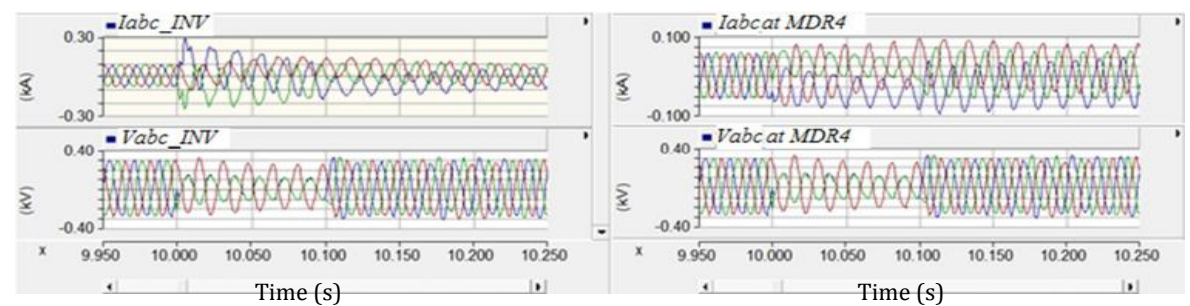

(a) Currents and voltages at MDR4 and the PV inverter's output regarding a LL fault $\mathrm{F}_{3-2}$ at the $10^{\text {th }}$ second.

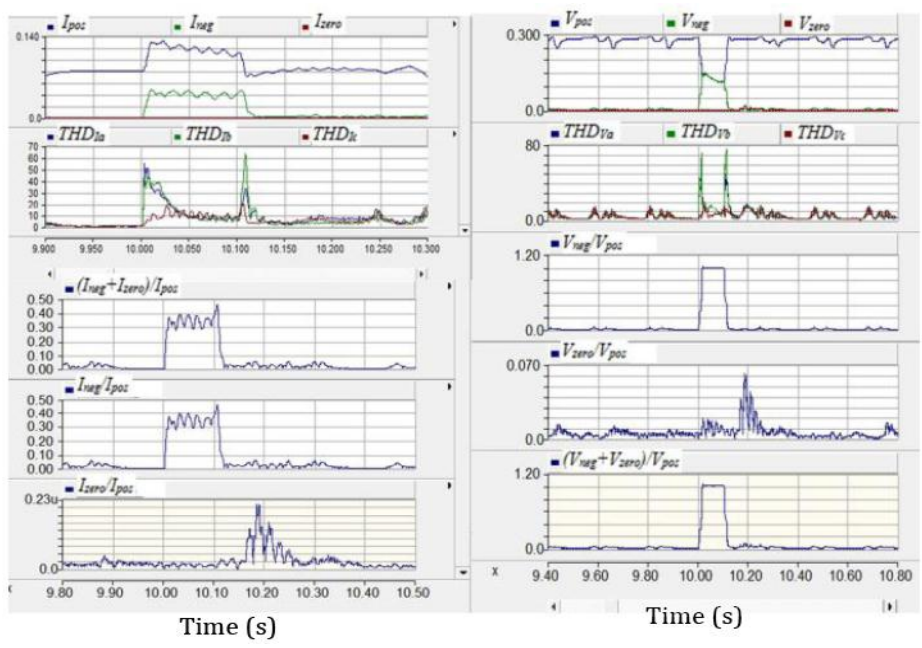

(b) Parameters measured at the PV inverter's output regarding a LL fault $\mathrm{F}_{3-2}$ at the $10^{\text {th }}$ second.
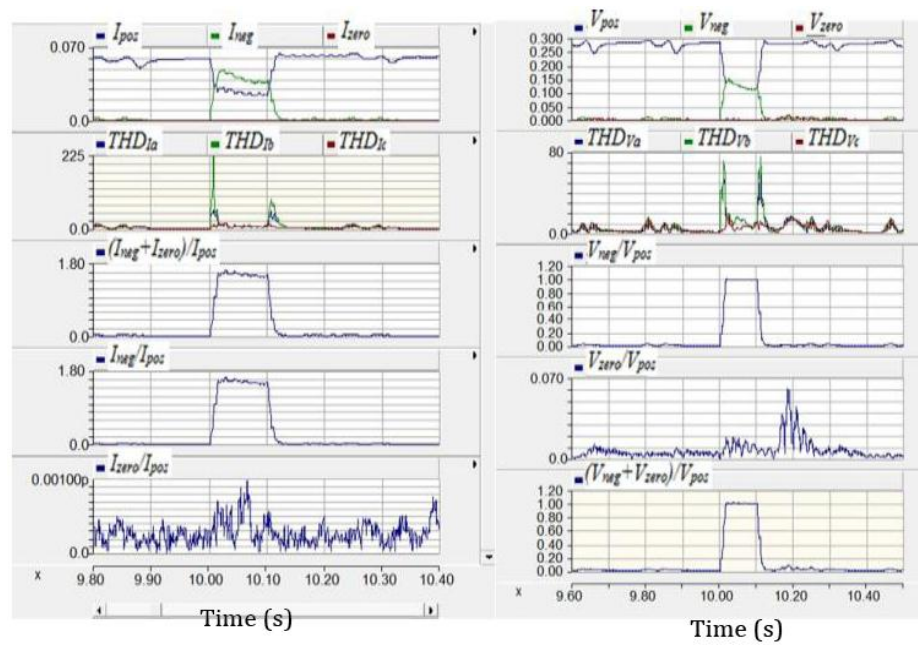

(c) Parameters measured at MDR4 regarding a LL fault $\mathrm{F}_{3-2}$ at the $10^{\text {th }}$ second.

Fig. 10. Fault parameters observed at MDR4 and the inverter's output in a PV branch with regard to a LL fault $\mathrm{F}_{3-2}$ at the $10^{\text {th }}$ second. 


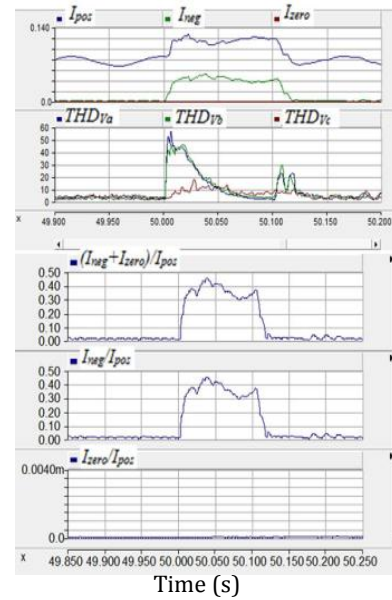

(a) Parameters measured at the PV inverter's

output at the $50^{\text {th }}$ second.

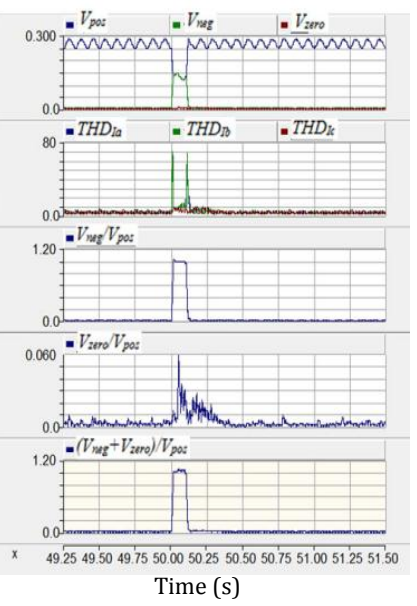

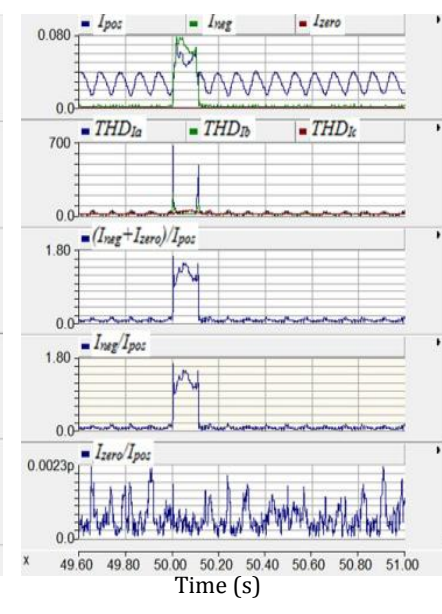

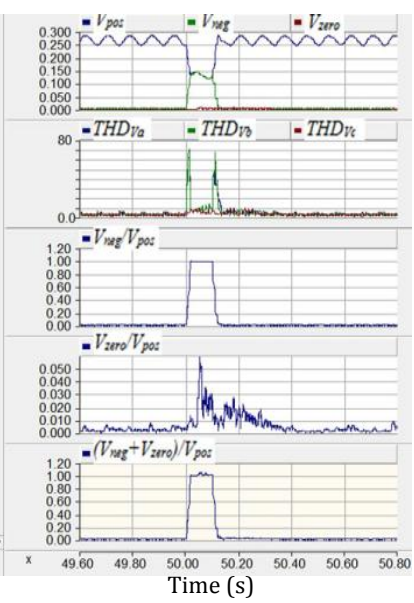

(b) Parameters measured at MDR4 regarding a LL fault $\mathrm{F}_{3-2}$ at the $50^{\text {th }}$ second.

Fig. 11. Fault parameters observed at MDR4 and at the PV inverter's output in a PV branch regarding a LL fault $\mathrm{F}_{3-2}$ at the $50^{\text {th }}$ second.

\subsection{Transient Simulation Results of an Operation Transition Test of Ungrounded MGs}

In order to distinguish between transient behaviours of fault situations and those of operation transition cases of an ungrounded MG, Fig. 12 shows the instant changes in values of parameters $T H D_{I a}, T H D_{I b}, T H D_{I c}$, $T H D_{V a}, T H D_{V b}, T H D_{V c}, I_{\text {pos }}, I_{\text {neg }}, I_{\text {zero }}, V_{\text {pos }}, V_{\text {neg }}, V_{\text {zero }},\left|I_{\text {neg }}\right| /\left|I_{\text {pos }}\right|,\left|I_{\text {zero }}\right| /\left|I_{\text {pos }}\right|, \quad\left(\left|I_{\text {neg }}\right|+\left|I_{\text {zero }}\right|\right) /\left|I_{\text {pos }}\right|,\left|V_{\text {neg }}\right| /\left|V_{\text {pos }}\right|$, $\left|V_{\text {zero }}\right| /\left|V_{\text {pos }}\right|$, and $\left(\left|V_{\text {neg }}\right|+\left|V_{\text {zero }}\right|\right) /\left|V_{\text {pos }}\right|$ with respect to a line-to-ground fault occurring at a location $\mathrm{F}_{2}$ with fault inception time at the $50^{\text {th }}$ second and an operation transition test of the ungrounded MG from an islanded mode into a grid-connected mode at the $60^{\text {th }}$ second. Based on simulation results in Fig. 12, values of the ratios $\left|V_{\text {neg }}\right| /\left|V_{\text {pos }}\right|,\left|I_{\text {neg }}\right| /\left|I_{\text {pos }}\right|,\left(\left|I_{\text {neg }}\right|+\left|I_{\text {zero }}\right|\right) /\left|I_{\text {pos }}\right|,\left(\left|V_{\text {neg }}\right|+\left|V_{\text {zero }}\right|\right) /\left|V_{\text {pos }}\right|$, and THD values of phase currents and voltages observed from a LG fault situation have a significant increase many times higher than those observed from a operation transition test of the ungrounded AC microgrid. Moreover, positive and negative sequence currents and voltages can be used to differentiate between the fault and the MG operation transition. Change in values of zero-sequence current and voltage are ineffective to distinguish between the faults and the operation transition of an ungrounded AC microgrid.
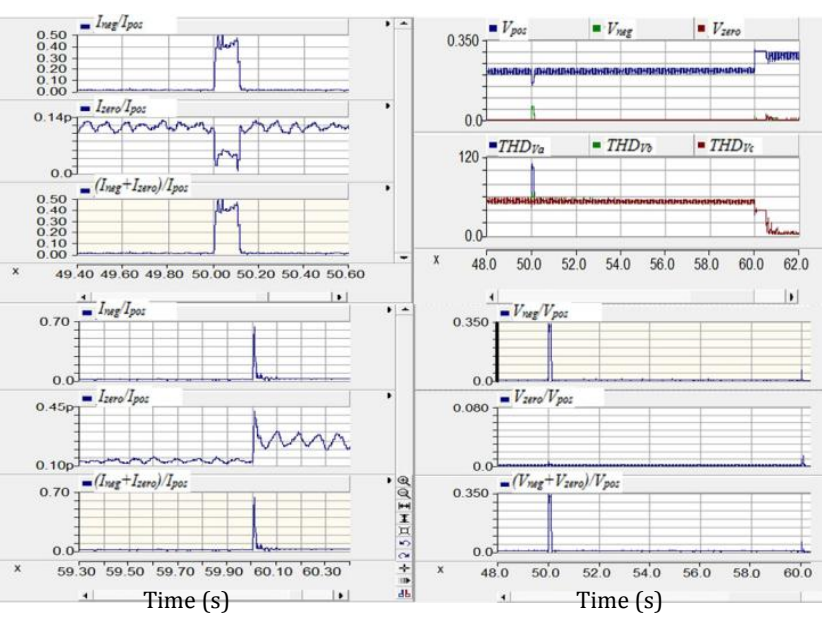

(a) Parameters measured at the LG fault time (the

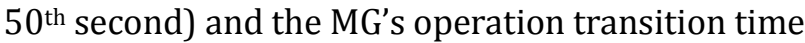
(the $60^{\text {th }}$ second) at MDR7.
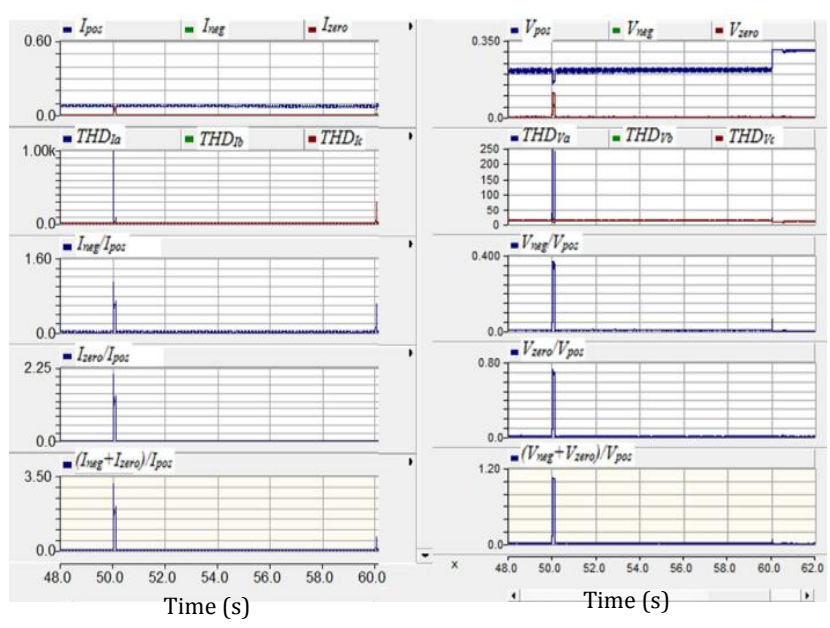

(b) Parameters measured at the LG fault time (the $50^{\text {th }}$ second) and the $\mathrm{MG}^{\prime}$ 's operation transition time (the 60 $0^{\text {th }}$ second) at MDR6.

Fig. 12. Transient responses of a LG fault and MG's operation transition. 


\subsection{Evaluation and Combination of Proposed Ungrounded AC Microgrid Fault Protection Solutions}

Table 4 shows evaluations of fault protection solutions proposed for ungrounded AC MGs that are focused on the fault protection of power converters, DG source branches, load branches, trunk lines, and common buses. More clearly, the evaluations of the fault protection solutions corresponding to individual protection zones of an ungrounded MG are based on transient simulation results of a typical ungrounded LVAC MG aforementioned. Necessary combinations among possible fault protection solutions of an ungrounded AC MG are also indicated in Table 4 through selecting primary and back-up protection solutions.

Table 4. Evaluating Fault Protection Solutions Proposed for Power Converters, Source Branches, Load Branches, Trunk Lines, and AC Common Buses in Ungrounded AC Microgrids

\begin{tabular}{|c|c|c|}
\hline $\begin{array}{l}\text { Individual protection zones of } \\
\text { an ungrounded LVAC microgrid }\end{array}$ & $\begin{array}{l}\text { Protection } \\
\text { types }\end{array}$ & $\begin{array}{l}\text { Evaluation and combination of the proposed fault protection solutions } \\
\text { for the microgrid primary and back-up protection }\end{array}$ \\
\hline \multirow{6}{*}{$\begin{array}{l}\text { 1. Fault protection of power } \\
\text { converters }\end{array}$} & \multirow{3}{*}{$\begin{array}{l}\text { Primary } \\
\text { protection }\end{array}$} & Under-voltage protection (27) \\
\hline & & Under-/over-frequency protection $(81 \mathrm{U} / 0)$ \\
\hline & & Relays using $I_{\text {neg }}$ and $V_{\text {neg }}$ (relays 46 and 47 , respectively) \\
\hline & \multirow[b]{3}{*}{$\begin{array}{l}\text { Back-up } \\
\text { protection }\end{array}$} & $\begin{array}{l}\text { Total harmonic distortion detection of currents and voltages: For } \\
\text { ungrounded AC microgrids, THD of current and voltage can be high in } \\
\text { cases of high penetration of inverter-based DGs or power unbalance. }\end{array}$ \\
\hline & & $\begin{array}{l}\text { Using the ratios }\left|I_{\text {neg }}\right| /\left|I_{\text {pos }}\right|, \quad\left|V_{\text {neg }}\right| /\left|V_{\text {pos }}\right|, \quad\left(\left|I_{\text {zero }}\right|+\left|I_{\text {neg }}\right|\right) /\left|I_{\text {pos }}\right| \text {, or } \\
\left(\left|V_{\text {zero }}\right|+\left|V_{\text {neg }}\right|\right) /\left|V_{\text {pos }}\right| \text { (referred to transient simulation results with respect } \\
\text { to line-to-line and line-to-ground faults at a } \mathrm{F}_{3-2} \text { location) }\end{array}$ \\
\hline & & $\begin{array}{l}\text { Using } 3 I_{0} \text { and } 3 V_{0} \text { components: With respect to an ungrounded } \mathrm{AC} \\
\text { microgrid, current/voltage unbalance usually occurs when the } \\
\text { one-phase or three-phase loads power is changed. Therefore, it is } \\
\text { needed to accurately differentiate about } 3 I_{0} \text { and } 3 V_{0} \text { values between } \\
\text { faults and load unbalance cases. Besides that, a problem of neutral point } \\
\text { shift in the ungrounded MG can increase the values of } 3 I_{0} \text { and } 3 V_{0} \text {, which } \\
\text { can lead to mal-operation of the inverter protection. As a result, } 3 I_{0} \text { and } \\
3 V_{0} \text { based methods are only considered for back-up protection of DC/AC } \\
\text { inverters in ungrounded AC MGs. }\end{array}$ \\
\hline \multicolumn{3}{|l|}{ 2. Fault protection of DG branches } \\
\hline \multirow{5}{*}{$\begin{array}{l}\text { At an islanded operation mode } \\
\text { of ungrounded microgrids }\end{array}$} & \multirow{2}{*}{$\begin{array}{l}\text { Primary } \\
\text { protection }\end{array}$} & Under-/over-voltage protection (27/59) \\
\hline & & Negative-sequence current and voltage based protection (46 and 47) \\
\hline & \multirow{3}{*}{$\begin{array}{l}\text { Back-up } \\
\text { protection }\end{array}$} & Total harmonic distortion detection of currents and voltages \\
\hline & & $\begin{array}{l}\text { Using the ratios }\left|I_{\text {neg }}\right| /\left|I_{\text {pos }}\right|,\left|V_{\text {neg }}\right| /\left|V_{\text {pos }}\right|,\left(\left|I_{\text {zero }}\right|+\left|I_{\text {neg }}\right|\right) /\left|I_{\text {pos }}\right| \text {, or } \\
\left(\left|V_{\text {zero }}\right|+\left|V_{\text {neg }}\right|\right) /\left|V_{\text {pos }}\right| \text { (referred to transient simulation results with respect } \\
\left.\text { to LL and LG faults at } \mathrm{F}_{3-2}\right)\end{array}$ \\
\hline & & Using $3 I_{0}$ and $3 V_{0}$ components \\
\hline \multirow{7}{*}{$\begin{array}{l}\text { At a grid-connected operation } \\
\text { mode of ungrounded } \\
\text { microgrids }\end{array}$} & \multirow{4}{*}{$\begin{array}{l}\text { Primary } \\
\text { protection }\end{array}$} & Under-/over-voltage protection $(27 / 59)$ \\
\hline & & Negative-sequence current and voltage based protection (46 and 47) \\
\hline & & Non-directional overcurrent protection relays $(50,51,51 \mathrm{~V})$ \\
\hline & & Directional overcurrent protection relays (67) \\
\hline & \multirow{3}{*}{$\begin{array}{l}\text { Back-up } \\
\text { protection }\end{array}$} & Total harmonic distortion detection of currents and voltages \\
\hline & & $\begin{array}{l}\text { Using the ratios }\left|I_{\text {neg }}\right| /\left|I_{\text {pos }}\right|,\left|V_{\text {neg }}\right| /\left|V_{\text {pos }}\right|,\left(\left|I_{\text {zero }}\right|+\left|I_{\text {neg }}\right|\right) /\left|I_{\text {pos }}\right|, \text { or } \\
\left(\left|V_{\text {zero }}\right|+\left|V_{\text {neg }}\right|\right) /\left|V_{\text {pos }}\right|\end{array}$ \\
\hline & & Using $3 I_{0}$ and $3 V_{0}$ components \\
\hline \multirow{6}{*}{$\begin{array}{l}\text { 3. Fault protection of load } \\
\text { branches }\end{array}$} & \multirow{5}{*}{$\begin{array}{l}\text { Primary } \\
\text { protection }\end{array}$} & $\begin{array}{l}\text { Instantaneous and time-delayed overcurrent protection modules } \\
(50 / 51) \text { along with AC circuit breakers }(52)\end{array}$ \\
\hline & & Overcurrent protection relays combined with high-speed fuses \\
\hline & & Directional overcurrent protection relays (67) \\
\hline & & Under-voltage protection (27) \\
\hline & & Negative-sequence current-and voltage-based protection (46 and 47) \\
\hline & Back-up & Total harmonic distortion detection of currents and voltages \\
\hline
\end{tabular}


protection

4. Fault protection of AC trunk lines and common buses

Directional over-current relays (fault currents can be high enough to activate overcurrent relays in case of high penetration of DGs into

Protection of trunk lines or common buses without any connection of load branches to the protected buses ungrounded microgrids)

\begin{tabular}{ll} 
Primary $\begin{array}{l}\text { protection \& } \\
\text { Back-up } \\
\text { protection }\end{array}$ & $\begin{array}{l}\text { Differential protection based on negative-sequence current components } \\
\text { or impedance components: These solutions are effective to detect } \\
\text { ground faults with the very small phase fault currents. }\end{array}$ \\
\cline { 2 - 2 } & $\begin{array}{l}\text { Pilot relays placed at terminals of trunk lines or common buses use } \\
\text { various fault protection principles (see Table 3) }\end{array}$ \\
\cline { 2 - 2 } $\begin{array}{l}\text { Admittance based protection principles } \\
\text { Primary } \\
\text { protection \& } \\
\begin{array}{l}\text { Back-up } \\
\text { protection }\end{array}\end{array}$ & $\begin{array}{l}\text { Directional over-current relays are very effective to detect the faults } \\
\text { when AC common buses contain load branches. }\end{array}$ \\
\cline { 2 - 2 } & $\begin{array}{l}\text { Differential protection based on negative-sequence current components } \\
\text { or impedance components }\end{array}$ \\
\cline { 2 - 2 } & Admittance based protection principles \\
\hline
\end{tabular}

\section{Discussion}

To investigate transient responses of a typical LVAC ungrounded microgrid, line-to-line and line-to-ground faults are assumed to occur at an AC trunk line, a common AC bus, and a PV source branch. Besides that, an operation transition case of the ungrounded microgrid is also investigated. Fault simulation results show that parameters $I_{\text {neg }}, V_{\text {neg }},\left|I_{\text {neg }}\right| /\left|I_{\text {pos }}\right|,\left(\left|I_{\text {neg }}\right|+\left|I_{\text {zero }}\right|\right) /\left|I_{\text {pos }}\right|,\left|V_{\text {neg }}\right| /\left|V_{\text {pos }}\right|,\left(\left|V_{\text {neg }}\right|+\left|V_{\text {zero }}\right|\right) /\left|V_{\text {pos }}\right|$, and THD values of phase currents and voltages can be applied for fault protection methods of power converters, DG source branches, load branches, AC trunk lines, and common buses; and the $3 I_{0}$ and $3 V_{0}$ components can be only utilized for back-up fault protection solutions in an ungrounded AC microgrid because of neural point shift and the power unbalance of three phases. Table 4 indicates that fast-acting fuses and power-electronic protective devices can be used to protect power converters and load branches; use of communication systems is needed to improve fault protection systems of ungrounded microgrids; and combination of primary and back-up fault protection solutions at each individual protection zone in an ungrounded microgrid into a digital relay will be an effective selection to design a microgrid protection system. The used digital relay should contain a variety of different primary and back-up protection modules of an ungrounded AC microgrid. On the other hand, possible fault protection solutions for each individual protection zone of an ungrounded microgrid are not compared in this paper, for example, comparison on total fault clearing time or their operation principles. These protection solutions are only evaluated based on their advantages and disadvantages as well as transient simulation results of a typical LVAC ungrounded microgrid. Then, the paper shows which fault protection solutions should be appropriately used as primary protection or back-up protection of ungrounded $\mathrm{AC}$ microgrids.

\section{Conclusion}

This paper has presented how to identify an ungrounded AC microgrid configuration based on three following conditions: (i) IBDGs only use 3-phase and 3-wire power converter interfaces to directly connect to the microgrid; (ii) IBDGs and RBDGs use ungrounded isolation transformers to connect to the microgrid; and (iii) distributed generators and energy storage devices are not grounded. A generalized fault protection structure of ungrounded AC microgrids is divided into six different protection zones. Due to reviewing the existing MG protection systems and analysing transient simulation results of the ungrounded AC microgrid, available fault protection solutions are proposed for each protection zone in an ungrounded AC MG. Moreover, selection among proposed fault protection solutions to design primary protection and back-up protection for power converters, source and load branches, trunk lines, and common buses in an 
ungrounded AC microgrid is done. Thereby, technicians can properly select which main and back-up protection methods are optimal for their ungrounded microgrids.

\section{Acknowledgment}

The authors gratefully acknowledge financial support and cooperation of Institute of Nuclear Energy Research-Taiwan for accomplishing this project (a contract number - MOST 104-3113-E-042A-004-CC2). Additionally, the authors also greatly thank to everyone at Chung Yuan Christian University-Taiwan for their valuable helps to the project.

\section{References}

[1] Lasseter, R. H. (2007). Certs microgrid. Proceedings of SoSE '07 IEEE International Conference on System of Systems Engineering (pp. 1-5).

[2] Driesen, J., Vermeyen, P., \& Belmans, R. (2007). Protection issues in microgrids with multiple distributed generation units. Proceedings of Power Conversion Conference (pp. 646-653). Nagoya, Japan.

[3] Sortomme, E., Mapes, G. J., Foster, B. A., \& Venkata, S. S. (2008). Fault analysis and protection of a microgrid. Proceedings of $40^{\text {th }}$ North Amer. Power Symposium (pp. 1-6).

[4] Nikkhajoei, H., \& Lasseter, R. H. (2006). Microgrid Fault Protection Based on Symmetrical and Differential Current Components (No. 500-03-024). Consortium for Electric Reliability Technology Solutions.

[5] Nikkhajoei, H., \& Lasseter, R. H. (2007). Microgrid protection. Proceedings of IEEE Power Eng. Soc. Gen. Meeting (pp. 1-6). Tampa, FL, USA.

[6] Al-Nasseri, H., Redfern, M. A., \& O'Gorman, R. (2005). Protecting microgrid systems containing solid-state converter generation. Proceedings of Int. Conf. Future Power Syst.

[7] Al-Nasseri, H., \& Redfern, M. A. (2007). A new voltage based relay scheme to protect micro-grids dominated by embedded generation using solid state converters. Electricity Distribution, 1-4.

[8] Al-Nasseri, H., Redfern, M. A., \& Li, F. (2006). A voltage based protection for micro-grids containing power electronic converters. Proceedings of Power Engineering Society General Meeting. Montreal.

[9] Hou, C. H. (2009). A study of voltage detection based fault judgment method in microgrid with inverter interfaced power source. Proceedings of International Conference on Electrical Engineering.

[10] Ritwik, M., et al. (2011). Control and protection of a microgrid connected to utility through back-to-back converters. Electric Power Systems Research, 81(7), 1424-1435.

[11] Dewadasa, M., Majumder, R., Ghosh, A., \& Ledwich, G. (2009). Control and protection of a microgrid with converter interfaced micro sources. Proceedings of Int. Conference on Power Systems (pp. 1-6).

[12] Samantaray, S. R., Joos, G., \& Kamwa, I., (2012). Differential energy based microgrid protection against fault conditions. Proceedings of Innovative Smart Grid Technologies (pp. 1-7).

[13] Wentao, H., et al. (2014). An impedance protection scheme for feeders of active distribution networks. IEEE Transactions on Power Delivery, 29(4), 1591-1602.

[14] Bolandi, T. G., Seyedi, H., Hashemi, S. M., et al. (2015). Impedance-differential protection: A new approach to transmission-line pilot protection. IEEE Transactions on Power Delivery, 30(6), 2510-2518.

[15] Ukil, A., Deck, B., \& Shah, V. H. (2011). Current-only directional overcurrent relay. IEEE Sensors Journal, 11(6), 1403-1404.

[16] Ukil, A., Deck, B., \& Shah, V. H. (2012). Current-only directional overcurrent protection for distribution automation: Challenges and solutions. IEEE Transactions on Smart Grid, 3(4), 1687-1694.

[17] Jalilian, A., Hagh, M. T., \& Hashemi, S. M. (2014). An innovative directional relaying scheme based on postfault current. IEEE Transactions on Power Delivery, 29(6), 2640-2647. 
[18] Saleh, K. A., Zeineldin, H. H., et al. (2015). Optimal coordination of directional overcurrent relays using a new time-current-voltage characteristic. IEEE Transactions on Power Delivery, 30(2), 537-544.

[19] Ndjaba, S., et al. (2012). Modelling and simulation of fault detection methods for power electronic interfaced microgrids. Proceedings of the 47th Universities Power Engineering (pp. 1-6).

[20] Al-Nasseri, H., \& Redfern, M. A., (2008). Harmonics content based protection scheme for micro-grids dominated by solid state converters. Proceedings of 12th Int. Middle East Power Systems (pp. 50-56).

[21] Jang, S., \& Kim, K. (2004). An islanding detection method for distributed generations using voltage unbalance and total harmonic distortion of current. IEEE Trans. Power Delivery, 19, 745-752.

[22] Bakara, A. H. A., et al. (2014). High impedance fault location in $11 \mathrm{kV}$ underground distribution systems using wavelet transforms. International Journal of Electrical Power \& Energy Systems, 55, 723-730.

[23] Xinyao, L., et al. (2014). Traveling wave-based protection scheme for inverter-dominated microgrid using mathematical morphology. IEEE Transactions on Smart Grid, 5(5), 2211-2218.

[24] Eissa, M. M., et al. (2006). A new protection detection technique for high impedance fault using neural network. Proceedings of Large Engineering Systems Conference on Power Engineering (pp. 146-151).

[25] David, C. T. W., \& Xia, Y. (1998). A novel technique for high impedance fault identification. IEEE Transactions on Power Delivery, 13, 738-744.

[26] Jota, F. G., \& Jota, P. R. S. (1998). High-impedance fault identification using a fuzzy reasoning system. IEE Proceedings-Generation, Transmission and Distribution, 145, 656-661.

[27] Yong, S., \& Rovnyak, S. M. (2004). Decision tree-based methodology for high impedance fault detection. IEEE Transactions on Power Delivery, 19, 533-536.

[28] Joós, G., \& El-Arroudi, K. (2007). Modeling protection for DGs and microgrids using data mining. Proceedings of Nagoya Microgrid Symposium. Retrieved September 30, 2015, from http://der.lbl.gov/sites/der.lbl.gov/files/nagoya joos.pdf

[29] Han, Y., Hu X., \& Zhang, D. (2010). Study of adaptive fault current algorithm for microgrid dominated by inverter based distributed generators. Proceedings of 2nd IEEE international Symposium on Power Electronics for Distributed Generation Systems (pp. 852-854). Hefei, China.

[30] Oudalov, A., \& Fidigatti, A. (2009). Adaptive network protection in microgrids. International Journal of Distributed Energy Resources, 5(3), 201-225.

[31] Khederzadeh, M. (2012). Adaptive setting of protective relays in microgrids in grid connected and autonomous operation. Proceedings of International Conference on Developments in Power Systems Protection. Birmingham, UK.

[32] Ustun, T. S., Ozansoy, C., \& Zayegh, A. (2011). A Central Microgrid Protection System for Networks with Fault Current Limiters. Proceedings of Int. Conference on Environment and Electrical Engineering.

[33] Tumilty, R. M., Brucoli, M., Burt, G. M., \& Green, T. C. (2006). Approaches to network protection for inverter dominated electrical distribution systems. Proceedings of the 3rd IET International Conference on Power Electronics, Machines and Drives (pp. 622-626). Dublin, Ireland.

[34] Dang, K., He, X., Daqiang, B., \& Cunliang, F. (2011). An adaptive protection method for the inverter dominated microgrid. Proceedings of Int. Conference on Electrical Machines and Systems Beijing, China.

[35] Laaksonen, H., Ishchenko D., \& Oudalov, A. (2014). Adaptive protection and microgrid control design for Hailuoto Island. IEEE Transactions on Smart Grid, 5(3), 1486-1493.

[36] McArthur, S. D. J., et al. (2007). Multi-agent systems for power engineering applications — Part I: Concepts, approaches, and technical challenges. IEEE Trans. on Power Systems, 22(4), 1743-1752.

[37] McArthur, S. D. J., et al. (2007). Multi-agent systems for power engineering applications - Part II: Technologies, standards, and tools for building multi-agent systems. IEEE Transactions on Power Systems, 22(4), 1753-1759. 
[38] Ananda, A., \& Gu, J. (2013). Multi-agent Based Protection on highly dominated distributed energy resources. Energy and Power Engineering, 5(4B), 927-931.

[39] Sheng, S., Li, K. K., \& Chan, W. L. (2010). Adaptive agent-based wide-area current differential protection system. IEEE Transactions on Industry Applications, 46(5), 2111-2117.

[40] Yu, Y. M., \& Li, Z. Y. Application of multi-agent system for adaptive protection system. Science Paper Online. From http://www.paper.edu.cn

[41] Gao, H., et al. (2012). New type of protection and control method for smart distribution grid. Proceedings of 11th International Conference on Developments in Power Systems Protection (pp. 24-24).

[42] Yanxia, C., et al. (2002). Research on protective relaying systems based on multi-agent system. Proceedings of International Conference on Power System Technology: Vol. 2 (pp. 661-665).

[43] Zhao, Q., \& Shuguang, L. (2011). Relay protection based on multi-agent system. Proceedings of 2011 International Conference on Electrical and Control Engineering (pp. 286-289).

[44] Cai, J. Y., et al. (2004). Current status and prospect of wide-area protection (dynamic stability control) technologies. Power System Technology, 28(8), 20-25.

[45] Jian, X., et al. (2008). Wide-area protection and its applications. Proceedings of Power Systems Conference and Exposition (pp. 22-35).

[46] Wei, C., et al. (2006). A wide area protective relaying system based on current differential protection principle. Power System Technology, 30(5), 91-95.

[47] Lei, L., et al. (2012). Wire-area protection in smart grids. Proceedings of 2012 International Conference on Future Energy, Environment, and Materials: Vol. 16 (pp. 1601-1606).

[48] Ustun, T. S., Ozansoy, C., \& Zayegh, A. (2012). Modelling of a centralized microgrid protection system and distributed energy resources according to IEC 61850-7-420. IEEE Transactions on Power Systems, 27(3), 1560-1567.

[49] Cornelis, A. P., \& Timothy, C. G. (2014). Fault response of inverter interfaced distributed generators in grid-connected applications. Electric Power Systems Research, 106, 21-28.

[50] Jayawarna, N., \& Barnes, M. (2009). Central storage unit response requirement in 'Good Citizen' microgrid. Proceedings of the 13th European Conference on Power Electronics and Applications (pp. 110). Barcelona, Spain.

[51] Oudalov, A., (2009). Novel Protection Systems for Microgrids. No. SES6-019864, TC2 Technical Requirements for Network Protection.

[52] Duong, B. M., Lien, K. Y., Chen, S. L., Lu, Y. C., Chan, C. M., \& Chang, Y. R. (2015). Investigate dynamic and transient characteristics of microgrid operation and develop a fast-scalable-adaptable algorithm for fault protection system. Electric Power Systems Research, 120, 214-233.

[53] Duong, B. M., et al. (2014). Review on protection coordination strategies and development of an effective protection coordination system for DC microgrid. Proceedings of 6th IEEE PES Asia-Pacific Power and Energy Engineering Conference (pp. 1-10).

[54] IEEE Application Guide for IEEE Std. 1547 ${ }^{\text {TM }}$, IEEE Standard for Interconnecting Distributed Resources with Electric Power Systems, IEEE Std. 1547.2-2008.

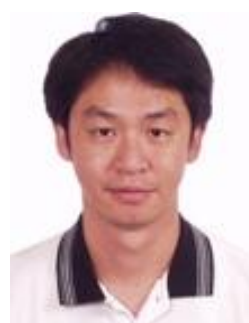

Keng-Yu Lien was born in 1969, Taiwan. He received his B.Sc. degree from National Tsing Hua University, Taiwan, and Ph.D. degree in electrical engineering from the same university, in 1991, 1998, respectively. In 1998, he joined the Industrial Technology Research Institute as a researcher of Electrical/Electromagnetic Measurement Laboratory. In 2003, he joined the Faculty of China University of Science and Technology, Taiwan, where he is currently an assistant professor. His current research interests include power 
system protection, micro-grid system protection and SOC development.

Duong Minh Bui was born in 1986, Vietnam. He received a bachelor degree in electrical engineering from CanTho University, Vietnam in 2008 and a master degree in electrical power engineering from University of Greenwich, United Kingdom in 2012. He is working towards a Ph.D. degree in electrical engineering at Chung Yuan Christian University, Taiwan.

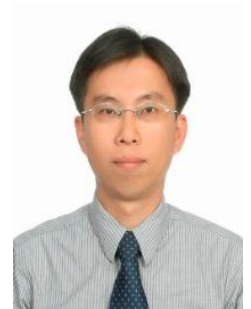

Yung-Ruei Chang received his $\mathrm{PhD}$ degree in electrical engineering from National Taiwan University in 2004. He is now the deputy director of Nuclear Instrumentation Division of the Institute of Nuclear Energy Research (INER), Atomic Energy Council, Taiwan, where he has been working since 1996. Since 2005, he has been responsible for power conditioning systems of the renewable energy project and leaded the distributed generation research group of INER. In 2007, he was a visiting scholar at the Future Energy Electronics Center of Virginia Polytechnic and State University, USA, where he joined to develop a high-efficiency DC-DC converter for solid oxide fuel cell. Now he is in charge of a microgrid project of INER. His research interests include microgrid technology, power electronic system, dependable computing, system reliability analysis and fault-tolerant system.

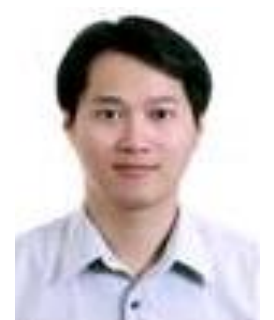

Yih-Der Lee received the B.S. and M.S. degrees in electrical engineering from National Taiwan University of Science and Technology (NTUST), Taipei, Taiwan, in 1997 and 1999, respectively. In 2009, he received the Ph.D. degree in electrical engineering from National Sun Yat-Sen University (NSYSU), Kaohsiung, Taiwan. From 1998 to 2010, he was an associate technical specialist at the Southern District Waste Management Plant, Environment Protection Bureau, Kaohsiung City Government. Since 2010, he joined the Institute of Nuclear Energy Research (INER), Atomic Energy Council, and currently is an associate researcher, which is responsible for developing smart grid technology. His research interests include renewable energy, microgrid, power electronics, power system control and stability. He is a member of the IEEE.

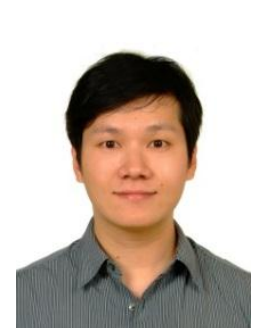

Jheng-Lun Jiang received the B.S. degrees in electrical engineering from National Kaohsiung University of Applied Sciences (KUAS), Kaohsiung, Taiwan, in 2007. He received his Ph.D. degree in electrical engineering from National Taiwan University of Science and Technology (NTUST), Taipei, Taiwan, in 2013. He is currently an associate developer with the Institute of Nuclear Energy Research (INER), Atomic Energy Council, Longtan, Taiwan. His research interests include renewable energy, microgrid, power system control and stability, and transient analysis.

Ching-Chih Lin was born on December 29, 1991, Taipei, Taiwan. He received the B.S. degree in electrical engineering from Chung Yuan Christian University (CYCU), Taoyuan, Taiwan, in 2014. Now he is an M.S. student in electrical engineering with CYCU, Taoyuan, Taiwan. 